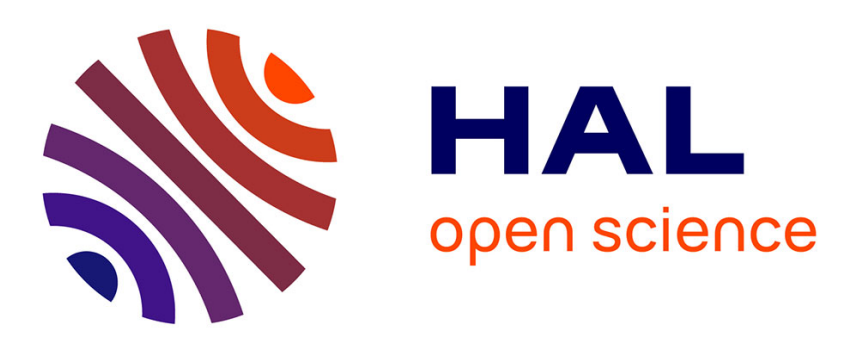

\title{
Origin of Intramolecular Low-Threshold Amplified Spontaneous Emission
}

Qi Wei, Ruihong H Duan, Qi Zhang, Linghai Xie, Ruidong Xia, Yuanping Yi, Jérémie Léonard, Stefan Haacke, Juan Cabanillas-gonzalez, Yan Qian, et al.

\section{- To cite this version:}

Qi Wei, Ruihong H Duan, Qi Zhang, Linghai Xie, Ruidong Xia, et al.. Origin of Intramolecular LowThreshold Amplified Spontaneous Emission. Advanced Optical Materials, 2021, 9 (12), pp.2001956. 10.1002/adom.202001956 . hal-03357454

\section{HAL Id: hal-03357454 https://hal.science/hal-03357454}

Submitted on 19 Nov 2021

HAL is a multi-disciplinary open access archive for the deposit and dissemination of scientific research documents, whether they are published or not. The documents may come from teaching and research institutions in France or abroad, or from public or private research centers.
L'archive ouverte pluridisciplinaire HAL, est destinée au dépôt et à la diffusion de documents scientifiques de niveau recherche, publiés ou non, émanant des établissements d'enseignement et de recherche français ou étrangers, des laboratoires publics ou privés. 


\section{Origin of Intramolecular Low-Threshold Amplified Spontaneous Emission}

Qi Wei ${ }^{\ddagger}$, Ruihong Duan ${ }^{*}$ Qi Zhang, Linghai Xie, Ruidong Xia, Yuanping Yi*, Jérémie Léonard, Stefan Haacke, Juan Cabanillas-Gonzalez*, Yan Qian*, and Wei Huang*

Prof. W. Huang, Prof. Y. Qian, Dr. Q. Wei, Dr. Q. Zhang, Prof. R. D. Xia, Prof. L. H. Xie Key Laboratory for Organic Electronics and Information Displays \& Institute of Advanced Materials (IAM), Jiangsu National Synergetic Innovation Center for Advanced Materials (SICAM), Nanjing University of Posts \& Telecommunications (NUPT), 9 Wenyuan Road, Nanjing 210023, China

E-mail: iamyqian@njupt.edu.cn, iamwhuang@njupt.edu.cn

Dr. R. H. Duan

College of Chemistry, Institute of Green Catalysis, Zhengzhou University, Zhengzhou, 450001, China.

Dr. R. H. Duan, Prof. Y. P. Yi

Beijing National Laboratory for Molecular Sciences, CAS Key Laboratory of Organic Solids, Institute of Chemistry, Chinese Academy of Sciences, Beijing, 100190, China

E-mail: ypyi@iccas.ac.cn

Prof. J. Léonard, Prof. S. Haacke

Université de Strasbourg, CNRS, Institut de Physique et Chimie des Matériaux de Strasbourg and Labex NIE, UMR 7504, F-67000 Strasbourg, France

Dr. J. Cabanillas-Gonzalez

IMDEA Nanoscience, Calle Faraday 9, Cantoblanco 28049, Madrid, Spain

E-mail: juan.cabanillas@imdea.org

Prof. W. Huang, Dr. Q. Wei

Key Laboratory of Flexible Electronics (KLOFE) \& Institute of Advanced Materials (IAM), Jiangsu National Synergetic Innovation Center for Advanced Materials (SICAM), Nanjing Tech University (NanjingTech), 30 South Puzhu Road, Nanjing 211816, China

\$The authors contributed equally to this work.

Keywords: organic lasers; organic semiconductors; amplified spontaneous emission 
Abstract: Amorphous thin films from solution-processable semiconductors are key materials for low-cost and large area optoelectronics. Design rules towards novel amorphous compounds with outstanding light emission and light amplification properties require understanding of the intimate relation between chemical and electronic structure. Here, we delicately design a series of compounds with tunable electronic transition characters of the lowest excited state, from local excited (LE), hybrid local charge-transfer (HLCT) to chargetransfer (CT) character. By deploying a combination of computational calculations and femtosecond-transient absorption experiments (TAS), we show that pure LE states strongly coupled to high wavenumber vibrational modes favors to form a few dominant discrete vibrational levels and are essential for optical gain, whereas HLCT or CT states preferably coupled to low frequency vibrational modes and forms a large number of consecutive vibrational levels which leads to broad excited-state absorption overwhelming stimulated emission. Our results provide guidelines for the rational design of efficient organic laser materials.

\section{Introduction}

Solid-state organic film lasers are promising broadly tunable coherent sources, which possess the benefits of low-cost processing, large compatibility with various substrates, and easy tuning of optoelectronic properties by molecular tailoring. ${ }^{[1-8]}$ In the last decades, the quest for electrically-pumped organic lasers has triggered a vast effort towards both the synthesis of organic semiconductors merging outstanding photonic and charge transport properties ${ }^{[9-15]}$ and towards the development of high quality factor laser cavities. ${ }^{[16,17]}$ From the materials design point of view, an optical gain medium must support excellent optical waveguiding ${ }^{[18,19]}$ as well as exhibit stimulated emission (SE) ${ }^{[20-22]}$. Whilst the former element relies on considerations of refractive index and homogeneity of the film (thickness value, thickness uniformity or absence of scattering inhomogeneities), SE depends on the photophysics of the 
film, being in particular sensitive to the nature of the lowest excited state responsible for emission and its associated features like radiative and non-radiative decay rates, concurrence of excited state absorption and SE in the same spectral regions or intramolecular electronphonon coupling. However, realization of amorphous thin-film organic lasers which generally exhibit a single amplified stimulated emission (ASE) is hindered by the lack of understanding the origin at the intramolecular level. General explanation of ASE is population inversion between two higher-energy levels, but it is too universal and still cannot tell which compounds easily feature population inversion and thus realize low-threshold ASE.

In this work we provide a direct visualization on how systematic chemical modification impacts on the SE properties of a new family of conjugated molecules, all sharing a common core consisting of a carbazole-substituted diarylfluorene. This bulky outof-plane central unit provides large steric hindrance, inhibiting severe aggregation and enabling prominent solid-state luminescence characteristics. ${ }^{[11,15,23]}$ Five different compounds are synthesized by connecting the common central diarylfluorene core with trifluoromethylphenyl-, fluorophenyl-, phenyl-, biphenyl- and fluorene- end groups which delicately confers their lowest excited states with a different character, from charge transfer (CT) by localization of the electron (hole) in the fluorene (carbazole) unit, to hybrid local charge-transfer (HLCT) or local excited (LE) characters. An in-depth investigation on the structure-property relationship is carried out in order to correlate the SE property with the nature of the lowest excited-states. We demonstrate that lowest CT states detrimental for SE can be de-stabilized in favor of LE states upon removing the electron withdrawing substituents and extending the conjugation around the fluorene core, giving rise to outstanding optical gain properties. This work has interesting implications for the rational design of organic laser materials.

\section{Results and discussion}


Five carbazole substituted arylfluorenes, namely $\mathrm{SFFC}, \mathrm{SCF}_{3} \mathrm{FCz}, \mathrm{SPhFC}, \mathrm{SBPhFCz}$ and SPFFCz, were synthesized by room-temperature $\mathrm{BF}_{3} \cdot \mathrm{Et}_{2} \mathrm{O}$-mediated Friedel-Crafts reaction of various tertiary alcohols of 2,7-aryl-substituted 9-phenyl-9H-fluoren-9-ol with 9-octyl-9Hcarbazole (see the chemical structures in Figure 1a and the synthesis routes in Scheme S1 in Supporting Information). The molecular structures and purities were confirmed by ${ }^{1} \mathrm{H}$ and ${ }^{13} \mathrm{C}$ NMR spectroscopy, MALDI-TOF MS and elemental analysis (See Supporting Information). The N-substituted octyl groups in the carbazole units enable large solubility and thus solution processability for film preparation. The substitution of the phenyl ring and carbazole via $\mathrm{sp}^{3}-\mathrm{C}$ of the 2,7-aryl-substituted fluorenes provide rotational flexibility of the former, bringing large steric hindrance, preventing otherwise severe emission quenching in condensed films and ensuring large thermal stabilities. Indeed, the fluorescence quantum efficiency $\left(\varphi_{\mathrm{f}}\right)$ values of SFFCz, $\mathrm{SCF}_{3} \mathrm{FCz}, \mathrm{SPhFCz}, \mathrm{SBPhFCz}$ and $\mathrm{SPFFCz}$ films are high: 52\%, 50\%, 39\%, 47\% and $66 \%$, respectively. The corresponding degradation temperatures were $436,377,451,459$, and $433^{\circ} \mathrm{C}$, respectively, while the glass transition temperatures were $87,134,88,124$ and $94^{\circ} \mathrm{C}$, respectively (see Figure S1 and S2 in Supporting Information). These moderately high glass transition temperatures suggest good film forming abilities of the five compounds.

As the carbazole units display a non-conjugated connection to $\mathrm{sp}^{3}-\mathrm{C}$ of the 9phenylfluorenes, the conjugation length is thus mainly determined by the parent chain of 2,7aryl-substituted 9-phenylfluorenes, hence depending on the different aryl substituents. Consistently, $\mathrm{SFFCz}, \mathrm{SCF}_{3} \mathrm{FCz}$ and $\mathrm{SPhFCz}$ (all with maximum absorption wavelength $\left(\lambda_{\mathrm{abs}}\right)$ around $303 \mathrm{~nm}$ ) exhibit almost identical absorption spectra, while $\mathrm{SBPhFCz}$ (with $\lambda_{\text {abs }}$ of 343 $\mathrm{nm}$ ) and SPFFCz (with $\lambda_{\text {abs }}$ of $355 \mathrm{~nm}$ ) show absorption red-shifts due to their larger conjugation lengths (Figure 1b and Figure S3 in Supporting Information).

Despite the identical absorption spectra of $\mathrm{SFFCz}, \mathrm{SCF}_{3} \mathrm{FCz}$ and $\mathrm{SPhFCz}$, their photoluminescence (PL) exhibit significant differences; $\mathrm{SPhFCz}$ possesses a vibronically resolved PL spectrum with maximum at $388 \mathrm{~nm}$ whereas $\mathrm{SFFCz}$ and $\mathrm{SCF}_{3} \mathrm{FCz}$ exhibit 
featureless PL with maxima at 417 and $413 \mathrm{~nm}$ respectively. SBPhFCz and SPFFCz with enhanced conjugation lengths show sharper, vibronically resolved PL and bathochromic shifts with maxima at 423 and $430 \mathrm{~nm}$ respectively. The PL dynamics in SBPhFCz and SPFFCz films follow mono-exponential decays with PL lifetimes of $760 \mathrm{ps}\left(k_{r}=6.2 \times 10^{8} \mathrm{~s}^{-1}\right)$ and 740 ps $\left(k_{r}=8.9 \times 10^{8} \mathrm{~s}^{-1}\right)$ respectively (see Figure S4, Table S1). Bi-exponential PL decays were instead found on $\mathrm{SFFCz}$ and $\mathrm{SCF}_{3} \mathrm{FCz}$ with amplitude-averaged lifetimes of $12.28 \mathrm{~ns}\left(k_{r}\right.$ $\left.=4.3 \times 10^{7} \mathrm{~s}^{-1}\right)$ and $13.64 \mathrm{~ns}\left(k_{r}=3.7 \times 10^{7} \mathrm{~s}^{-1}\right)$ respectively. Similarly, SPhFCz exhibits biexponential PL decay with $2.06 \mathrm{~ns}$ average lifetime $\left(k_{r}=1.89 \times 10^{8} \mathrm{~s}^{-1}\right)$. A summary of the PL emission peaks together with their $\varphi_{f}$ values, average PL lifetimes $\left(\tau_{a v}\right)$ and radiative (nonradiative) decay rates $k_{r}\left(k_{n r}\right)$ is shown in Table 1.

Optical gain from thin films was assessed with a widely described method consisting of pumping them with a pulsed narrow stripe of light and detecting the waveguided luminescence at the film edge. ${ }^{[11,14]}$ Among the five compounds, only SBPhFCz and SPFFCz exhibited amplified spontaneous emission (ASE), centered on the sharp 0-1 fluorescence peak at 419 and $426 \mathrm{~nm}$, respectively. The measured ASE thresholds of SBPhFCz and SPFFCz were 2.95 and $1.59 \mu \mathrm{J} / \mathrm{cm}^{2}$, respectively.

We first carried out time-dependent density functional theory (TDDFT) calculations in order to elucidate the excited-state electronic-structure properties of these related molecular structures (see the computational details in the Supporting Information). As seen in Figure 2 and Table $\mathrm{S} 2$, the lowest singlet exited state $\left(\mathrm{S}_{1}\right)$ of both $\mathrm{SFFCz}$ and $\mathrm{SCF}_{3} \mathrm{FCz}$ is a chargetransfer (CT) state with the hole located on the electron-donating carbazole unit while the electron being localized on the fluoro-biphenyl or trifluoromethyl-biphenyl fluorene units. Transitions from $S_{0}$ to $S_{1}$ are weakly allowed as confirmed by the low oscillator strength $(f)$ values associated to the CT states. In contrast with $S_{1}$, the second and third singlet excited states $\left(S_{2}\right.$ and $\left.S_{3}\right)$ have an increased hole localization on the biphenyl fluorene unit, giving rise 
to a hybrid local charge transfer (HLCT) character and relatively strong oscillator strengths in both of them. Regarding $\mathrm{SPhFCz}$, the $\mathrm{S}_{1}$ state has HLCT character whereas the $\mathrm{S}_{2}$ and $\mathrm{S}_{3}$ states have CT character and local excitation (LE) character on the carbazole unit, respectively. Both $\mathbf{S}_{2}$ and $\mathrm{S}_{3}$ share low $f$ values due to the associated transitions being symmetry forbidden. The $S_{1}$ state of $S P h F C z$ lies between the $S_{2}$ and $S_{3}$ levels of SFFCz or $\mathrm{SCF}_{3} \mathrm{FCz}$, agreeing with the similar absorption spectra of the three compounds (Figure $1 \mathrm{~b}$ ). On the other hand, because of the elongated conjugation, the $S_{1}$ states of $\mathrm{SBPhFCz}$ and SPFFCz become LE states on the bis(biphenyl) fluorene or terfluorene backbones, and exhibit much enhanced oscillator strengths as well as decreased excitation energies; however, the $S_{2}$ and $S_{3}$ states are CT states. Notably, the predicted $S_{1}$ characters of the five compounds are consistent with the presence/absence of PL spectral shifts in solvents with different polarity. Indeed, because of the $\mathrm{CT}$ character, $\mathrm{SFFCz}$ and $\mathrm{SCF}_{3} \mathrm{FCz}$ show large bathochromic shifts in the PL spectra upon replacing nonpolar $n$-hexane solvent by high polar acetonitrile (see Figure S5 in Supporting Information). Contrarily, the PL spectra of SBPhFCz and SPFFCz exhibit almost no shift upon changing the solvent polarity due to the LE character of $\mathrm{S}_{1}$. The HLCT character of $\mathrm{S}_{1}$ in $\mathrm{SPhFCz}$ is reflected in small shifts in solvents with no or weak polarity but large red-shifts in highly polar solvents.

The PL spectral shapes are also in line with the predicted character of $S_{1}$ in the different compounds. SBPhFCz and SPFFCz with LE character show clear vibronicallyresolved PL spectra whereas the other three compounds with CT or HLCT characters show broader featureless PL. To further reveal the influence of the transition characters on the emission spectra, we have theoretically calculated the fluorescence spectra and analyzed the role of molecular vibrations for $\mathrm{SFFCz}$ and $\mathrm{SBPhFCz}$, as representatives of $\mathrm{CT}$ and $\mathrm{LE}$ transitions, respectively. The calculated fluorescence spectra (Figure 3a) agree well with the experimental ones in $n$-hexane (Figure S3); SFFCz shows a single broad peak whereas $\mathrm{SBPhFCz}$ exhibits three distinguishable vibronic peaks with the $0-0$ transition slightly 
stronger than the 0-1 transition. Note that because of self-absorption effects in the solid phase, the 0-0 transition is much weaker than the 0-1 transition, as observed in the SBPhFCz film (Figure 1b). Based on the essential active vibrational modes (with Huang-Rhys factors $S>0.1$, see Figure 3b), the vibrational transition probabilities (so-called Franck-Condon factors, see Figure 3a) are calculated to be approximately a continuous curve for SFFCz but more discrete for $\mathrm{SBPhFCz}$. The enhanced vibronic structure of the $\mathrm{SBPhFCz} \mathrm{PL}$ is attributed to a decreased vibronic coupling of the low-frequency vibrational modes and a stronger vibronic coupling of the high-frequency backbone stretching modes (Figure 3b-c). The stronger vibronic couplings of the high-frequency vibrations increase the intensity of the $0-1$ sub-band whereas the stronger couplings of the low-frequency vibrations broaden the sub-bands and lead to less resolved PL spectra (Figure 3a, S6, and S7). As seen in Figure 3c, the strongest vibronic couplings in SFFCz are ascribed to low frequency torsional modes; for instance, $S=$ 6.2 at $14.5 \mathrm{~cm}^{-1}$ and 19.0 at $20.8 \mathrm{~cm}^{-1}$. The vibronic coupling is quadratically proportional to the normal mode displacement (see eq S3). ${ }^{[24,25]}$ In SFFCz, the torsional vibrations include all the moieties in the molecules and the inter-fragment displacements are particularly obvious (Figure 3c and S8a), due to the significant change in electronic density upon CT transition. This significant inter-fragment geometry change causes $\mathrm{SFFCz}$ to have large vibronic coupling in the very-low-frequency region, detrimental for the formation of the well-resolved vibronic peaks in the PL spectrum. Conversely, benefiting from the LE character of $S_{1}$, $\mathrm{SBPhCz}$ torsional vibrations are confined in the bis(biphenyl) fluorene fragment and there is no inter-fragment geometry change (Figure $3 c$ and S8b). In the low-frequency region, the largest vibronic couplings correspond to higher frequency modes for $\mathrm{SBPhCz}$, e.g. $S=1.2$ at $26.4 \mathrm{~cm}^{-1}$ and $S=4.8$ at $89.1 \mathrm{~cm}^{-1}$. This is advantageous to form discrete energy levels for efficient population inversion required in ASE. As a result, $\mathrm{SBPhCz}$ exhibits a narrower and fine-structured PL spectrum while SFFCz exhibit a broad spectral shape. These different PL spectral shapes have also implications in the optical gain properties of the five compounds 
since larger optical gain coefficients are generally expected when the PL is concentrated in a narrower spectral range. Thus, the narrower and well-resolved PL of SBPhFCz and SPFFCz affords a priori better characteristics for efficient ASE and lasing.

Further insights on the optical gain properties require monitoring SE and excited state absorption (ESA) in the time domain with femtosecond transient absorption spectroscopy. Figure 4 depicts the differential absorption $(\Delta \mathrm{A})$ spectra of the five compounds in film at time delays from 0.6 to 1900 ps upon photoexcitation at $320 \mathrm{~nm}(3.9 \mathrm{eV})$. Starting with SFFCz and $\mathrm{SCF}_{3} \mathrm{FCz}$ (Figure 4a-b), photoexcitation initially populates the $\mathrm{S}_{2}$ HLCT level (according to Figure 2a) which subsequently relaxes to the $\mathrm{S}_{1} \mathrm{CT}$ state by internal conversion. The $0.6 \mathrm{ps}$ $\triangle \mathrm{A}$ spectra of $\mathrm{SFFCz}$ and $\mathrm{SCF}_{3} \mathrm{FCz}$ are dominated by broad ESA from the $\mathrm{S}_{1} \mathrm{CT}$ state with maxima at 552 and $545 \mathrm{~nm}$ respectively with absence of negative $\Delta \mathrm{A}$ signal in the 400-450 $\mathrm{nm}$ range where SE is expected to be located. This is in line with the predicted very weak oscillator strength of the CT-S $\mathrm{S}_{0}$ transition (Fig 2a). Lack of SE is also evident at longer time delays whereas the spectra experience a slight blue shift towards $541 \mathrm{~nm}$ ascribed to vibrational cooling. The $\triangle \mathrm{A}$ spectra of $\mathrm{SPhFCz}$ at 0.6 ps delay (Figure $4 \mathrm{c}$ ) depicts strong ESA extending well beyond $600 \mathrm{~nm}$ with a shoulder around $550 \mathrm{~nm}$. As time elapses beyond $10 \mathrm{ps,}$ the tail vanishes leaving a prominent absorption band underneath with maximum at $549 \mathrm{~nm}$ and similar spectral characteristics as the one observed in $\mathrm{SFFCz}$ and $\mathrm{SCF}_{3} \mathrm{FCz}$. The presence of SE buried underneath the dominant ESA is plausible from the inverted PL-like shape of the valley between 370 and $450 \mathrm{~nm}$ absorption region. It appears that ESA has a higher oscillator strength than $\mathrm{SE}$, explaining the positive $\Delta \mathrm{A}$ in this spectral region. Absence of $\mathrm{SE}$ is also found in the $\Delta \mathrm{A}$ spectra of the three compounds in chloroform solution (Figure S9), confirming that the cause of SE quenching is merely intra-molecular. Clearly, these films show photo-induced loss rather than optical gain. Contrarily, the $\triangle \mathrm{A}$ spectra of $\mathrm{SBPhFCz}$ and SPFFCz (Figure 4d-e) reveal a very different photophysical scenario. Herein, the LE character 
of $S_{1}$ is manifested through the observation of a negative $\Delta \mathrm{A}$ band in the $400-440 \mathrm{~nm}$ spectral range (superposed with their respective PL spectra) due to SE, in line with the strong oscillator strength predicted for the $\mathrm{S}_{0}-\mathrm{LE}$ transition. At $0.6 \mathrm{ps}$ delay the $\mathrm{SE}$ band is accompanied by a falling tail in the short wavelength range $(350-400 \mathrm{~nm})$ assigned to ground state bleach and by a broad ESA with a maximum beyond $650 \mathrm{~nm}$ in the long wavelength range. The ESA becomes gradually broader and more pronounced on the central part of the visible spectrum. As a result, the $\Delta \mathrm{A}$ spectra above $34 \mathrm{ps}$ are composed of ground state bleach up to $375 \mathrm{~nm}$ followed by broad absorption centered around $525 \mathrm{~nm}$ and absence of SE. Importantly, this new contribution is apparently absent in the $\Delta \mathrm{A}$ spectra in solution (Figure S9), as revealed by the presence of SE in timescales up to $1 \mathrm{~ns}$. We ascribe this new built-in contribution to inter-chain polaron-pairs formed in the condensed phase, which are often reported in oligo- and polyfluorene films and characterized by similar broad photoinduced absorption in the green-yellow spectral range. ${ }^{[26-35]}$ In summary, $\mathrm{SFFCz}, \mathrm{SCF}_{3} \mathrm{FCz}$ and $\mathrm{SPhFCz}$ do not display stimulated emission (SE) in line with the very low oscillator strength associated to their lower $\mathrm{S}_{1}$ excited states; the $400-500 \mathrm{~nm}$ spectral range of the $\Delta \mathrm{A}$ spectra is in all cases dominated by ESA, explaining their inability to generate optical gain, and absence of ASE. This is mainly ascribed to the detrimental presence of CT and HLCT states showing predominant ESA over SE. ${ }^{[36,37]}$ Contrarily, spatial elongation of the aryl-substituted fluorene-phenyl arms in SBPhFCz and SPFFCz lifts up the CT states favoring the formation of lowest LE excited states. These LE states have a much higher oscillator strength (Figure 2) and are strongly and preferentially coupled to high frequency modes located in the bis(biphenyl) fluorene fragment, leading to narrower vibronically resolved lineshape distributions. Altogether, this largely favors SE over ESA.

\section{Conclusion}


In conclusion, a series of carbazole substituted arylfluorenes with different $\mathrm{CT}$ and LE excited-state contributions tuned by varying their conjugation lengths and substituents have been synthesized and studied. Due to the different energy level ordering of their LE (or HLCT) and CT excited states, only SBPhFCz and SPFFCz bearing longer conjugation length and lowest-lying LE state exhibit low-threshold ASE. Strong coupling of LE states with few high frequency modes leads to the presence of strong vibronically resolved SE overwhelming the long tail of ESA. Contrarily, short conjugated $\mathrm{SCF}_{3} \mathrm{FCz}$ and $\mathrm{SFFCz}(\mathrm{SPhFCz})$ depict lowest CT (HLCT) states with negligible SE contribution overwhelmed by ESA. This work highlights the importance of pure LE states stabilized by an extended conjugation and absence of push-pull charge effects on the fluorine moieties, gives enlightenment for future rational design of the organic laser materials.

\section{Experimental Section}

The synthesis and characterization of the five materials are described in SI. UV-vis absorption and PL spectra were recorded using a Shimadzu UV-3150 and RF-5300PC spectrometer, respectively. Lifetimes were measured using an Edinburgh FLSP-920 lifetime spectrometer with a $375 \mathrm{~nm}$ laser (typical pulse width: $55 \mathrm{ps}$; pulse repetition frequencies: $20 \mathrm{MHz}$ ). For ASE measurements, the samples were optically pumped at $375 \mathrm{~nm}$ with a Q-switched, neodymium ion doped yttrium aluminum garnet $\left[\mathrm{Nd}^{3+}: \mathrm{YAG}\right]$ laser $(3 \mathrm{~ns}$ pulses at a repetition rate of $10 \mathrm{~Hz}$ ) with a cylindrical lens to form a $4 \mathrm{~mm} \times 550 \mu \mathrm{m}$ stripe-shaped excitation area on the sample. The threshold is defined as the pump intensity at which the FWHM linewidth of the emission spectrum halves.

In the TAS setup, an amplified $5 \mathrm{kHz}$ Ti: sapphire laser generates $30 \mathrm{fs} 0.5 \mathrm{~mJ}$ pulses to pump a commercial optical parametric amplifier (TOPAS: Light Conversion), from which 50-60 fs pulses are derived to excite the samples at $320 \mathrm{~nm}$. A white light continuum is generated in a $2 \mathrm{~mm}$ thick $\mathrm{CaF}_{2}$ crystal, mounted on an oscillating loudspeaker to reduce 
photo-damage. The beam is split in two: the probe that is sent through the sample, and a reference beam is used for measuring and compensating the white-light intensity fluctuations. The polarization of the probe beam is set at magic angle $\left(54.7^{\circ}\right)$ with respect to the pump. Time-resolved spectra $\mathrm{I}(\lambda)$ are acquired as a function of pump-probe delay, by a combination of $25 \mathrm{~cm}$ focal length spectrometer (resolution $2 \mathrm{~nm}$ ) and a Peltier-cooled CCD with $220 \mathrm{~Hz}$ acquisition rate. A second chopper blocks the pump beam at $110 \mathrm{~Hz}$ and a home-made software computes the differential spectra $\Delta A=-\log _{10}\left(\frac{I_{\text {pump-on }}}{I_{\text {pump-off }}}\right)$. A reference sample is measured, and the data are processed to (i) remove the background at negative delay times, (ii) the solvent Raman signal and the coherent interactions of the pump and probe in the cell, (iii) to correct for the group velocity dispersion of the probe beam, characterized in the solvent-only data set.

\section{Supporting Information}

Supporting Information is available from the Wiley Online Library or from the author.

\section{Acknowledgements}

Q. Wei and R. H. Duan contributed equally to this work. We thank the Ministry of Science and Technology of China (Grant No. 2018YFA0703200), the National Natural Science Foundation of China (Grant Nos. 21573111), the Priority Academic Program Development of Jiangsu Higher Education Institutions (PAPD, YX03001), Jiangsu National Synergetic Innovation Center for Advanced Materials (SICAM), Synergetic Innovation Center for Organic Electronics and Information Displays, Six Talents Peak Project of Jiangsu Province (XCL-076), Qing Lan Project of Jiangsu Province for their financial support. J.C-G acknowledges support from the Regional Government of Madrid through NMAT2D-CM project (S2018/NMT-4511) and RTI2018-097508-B-I00 (AMAPOLA). IMDEA Nanociencia acknowledges support from the "Severo Ochoa" Programme for Centers of Excellence in R\&D (MINECO, Grant SEV-2016-0686).

Received: ((will be filled in by the editorial staff))

Revised: ((will be filled in by the editorial staff)) Published online: ((will be filled in by the editorial staff))

\section{References}

[1] A. J. C. Kuehne, M. C. Gather, Chem. Rev. 2016, 116, 12823. 
[2] C. Grivas, M. Pollnau, Laser Photonics Rev. 2012, 6, 419.

[3] M. T. Hill, M. C. Gather, Nat. Photonics 2014, 8, 908.

[4] B. H. Wallikewitz, M. de la Rosa, J. H. W. M. Kremer, D. Hertel, K. Meerholz, Adv. Mater. 2010, 22, 531.

[5] E. B. Namdas, M. Tong, P. Ledochowitsch, S. R. Mednick, J. D. Yuen, D. Moses, A. J. Heeger, Adv. Mater. 2009, 21, 799.

[6] M. C. Gwinner, S. Khodabakhsh, M. H. Song, H. Schweizer, H. Giessen, H. Sirringhaus, Adv. Funct. Mater. 2009, 19, 1360.

[7] S. Chenais, S. Forget, Polym. Int. 2012, 61, 390.

[8] J. R. C. Smirnov, A. Sousaraei, M. R. Osorio, S. Casado, J. J. Hernández, L. Wu, Q.

Zhang, R. Xia, D. Granados, R. Wannemacher, I. Rodriguez, J. Cabanillas-Gonzalez, npj Flexible Electronics 2019, 3, 17.

[9] B. K. Yap, R. Xia, M. Campoy-Quiles, P. N. Stavrinou, D. D. Bradley, Nat. Mater. 2008, 7, 376.

[10] D. Amarasinghe, A. Ruseckas, A. E. Vasdekis, G. A. Turnbull, I. D. W. Samuel, Adv. Mater. 2009, 21, 107.

[11] W.-Y. Lai, R. Xia, Q.-Y. He, P. A. Levermore, W. Huang, D. D. C. Bradley, Adv. Mater. 2009, 21, 355.

[12] H. Kim, N. Schulte, G. Zhou, K. Müllen, F. Laquai, Adv. Mater. 2011, 23, 894.

[13] X. F. Jiang, Y. F. Xiao, C. L. Zou, L. N. He, C. H. Dong, B. B. Li, Y. Li, F. W. Sun, L. Yang, Q. H. Gong, Adv. Mater. 2012, 24, OP260.

[14] W. Xu, J. Yi, W.-Y. Lai, L. Zhao, Q. Zhang, W. Hu, X.-W. Zhang, Y. Jiang, L. Liu, W. Huang, Adv. Funct. Mater. 2015, 25, 4617.

[15] Y. Qian, Q. Wei, G. Del Pozo, M. M. Mroz, L. Lueer, S. Casado, J. CabanillasGonzalez, Q. Zhang, L. Xie, R. Xia, W. Huang, Adv. Mater. 2014, 26, 2937. 
[16] A. S. D. Sandanayaka, T. Matsushima, F. Bencheikh, S. Terakawa, W. J. Potscavage, Jr., C. Qin, T. Fujihara, K. Goushi, J.-C. Ribierre, C. Adachi, Appl. Phys. Express 2019, 12, 061010.

[17] O. Mhibik, S. Forget, D. Ott, G. Venus, I. Divliansky, L. Glebov, S. Chenais, LightScience \& Applications 2016, 5, e16026.

[18] K. Takazawa, Y. Kitahama, Y. Kimura, G. Kido, Nano Lett. 2005, 5, 1293.

[19] J. R. Castro Smirnov, Q. Zhang, R. Wannemacher, L. Wu, S. Casado, R. Xia, I. Rodriguez, J. Cabanillas-Gonzalez, Sci. Rep. 2016, 6, 34565.

[20] T. Virgili, J. Clark, J. Cabanillas-Gonzalez, L. Bazzana, K. C. Vishnubhatla, R. Osellame, R. Ramponi, G. Lanzani, J. Mater. Chem. 2010, 20, 519.

[21] C. Sun, M. Magdalena Mroz, J. R. Castro Smirnov, L. Luer, D. Hermida-Merino, C. Zhao, M. Takeuchi, K. Sugiyasu, J. Cabanillas-Gonzalez, J. Mater. Chem. C 2018, 6, 6591. [22] Y. Xu, G. Hai, H. Xu, H. Zhang, Z. Zuo, Q. Zhang, R. Xia, C. Sun, J. Castro-Smirnov, A. Sousaraei, S. Casado, M. R. Osorio, D. Granados, I. Rodriguez, J. Cabanillas-Gonzalez, Adv. Opt. Mater. 2018, 6, 1800263.

[23] Q. Wei, Y. Li, J. G. Liu, Q. Y. Fang, J. W. Li, X. H. Yan, L. H. Xie, Y. Qian, R. D. Xia, W. Huang, Adv. Opt. Mater. 2017, 5, 1601003.

[24] J. L. Bredas, D. Beljonne, V. Coropceanu, J. Cornil, Chem. Rev. 2004, 104, 4971.

[25] V. Coropceanu, J. Cornil, D. A. da Silva Filho, Y. Olivier, R. Silbey, J.-L. Bredas, Chem. Rev. 2007, 107, 926.

[26] T. Virgili, D. Marinotto, C. Manzoni, G. Cerullo, G. Lanzani, Phys. Rev. Lett. 2005, $94,117402$.

[27] V. Gulbinas, D. Hertel, A. Yartsev, V. Sundstrom, Phys. Rev. B 2007, 76, 235203.

[28] Y. Zaushitsyn, V. Gulbinas, D. Zigmantas, F. L. Zhang, O. Inganas, V. Sundstrom, A. Yartsev, Phys. Rev. B 2004, 70, 075202. 
[29] V. Gulbinas, Y. Zaushitsyn, V. Sundstrom, D. Hertel, H. Bassler, A. Yartsev, Phys. Rev. Lett. 2002, 89, 107401.

[30] T. Virgili, D. Marinotto, G. Lanzani, D. D. C. Bradley, Appl. Phys. Lett. 2005, 86, 091113.

[31] Q. Zhang, J. Liu, Q. Wei, X. Guo, Y. Xu, R. Xia, L. Xie, Y. Qian, C. Sun, L. Lueer, J. Cabanillas-Gonzalez, D. D. C. Bradley, W. Huang, Adv. Funct. Mater. 2018, 28, 1705824.

[32] O. J. Korovyanko, Z. V. Vardeny, Chem. Phys. Lett. 2002, 356, 361.

[33] A. Isakova, S. Karuthedath, T. Arnold, J. R. Howse, P. D. Topham, D. T. W. Toolan, F. Laquai, L. Luer, Nanoscale 2018, 10, 10934.

[34] J. Cabanillas-Gonzalez, G. Grancini, G. Lanzani, Adv. Mater. 2011, 23, 5468.

[35] M. A. Stevens, C. Silva, D. M. Russell, R. H. Friend, Phys. Rev. B 2001, 63, 165213.

[36] S. Varghese, S. K. Park, S. Casado, R. Resel, R. Wannemacher, L. Lueer, S. Y. Park, J. Gierschner, Adv. Funct. Mater. 2016, 26, 2349.

[37] M. Wykes, S. K. Park, S. Bhattacharyya, S. Varghese, J. E. Kwon, D. R. Whang, I. Cho, R. Wannemacher, L. Lueer, S. Y. Park, J. Gierschner, J. Phys. Chem. Lett. 2015, 6, 3682.
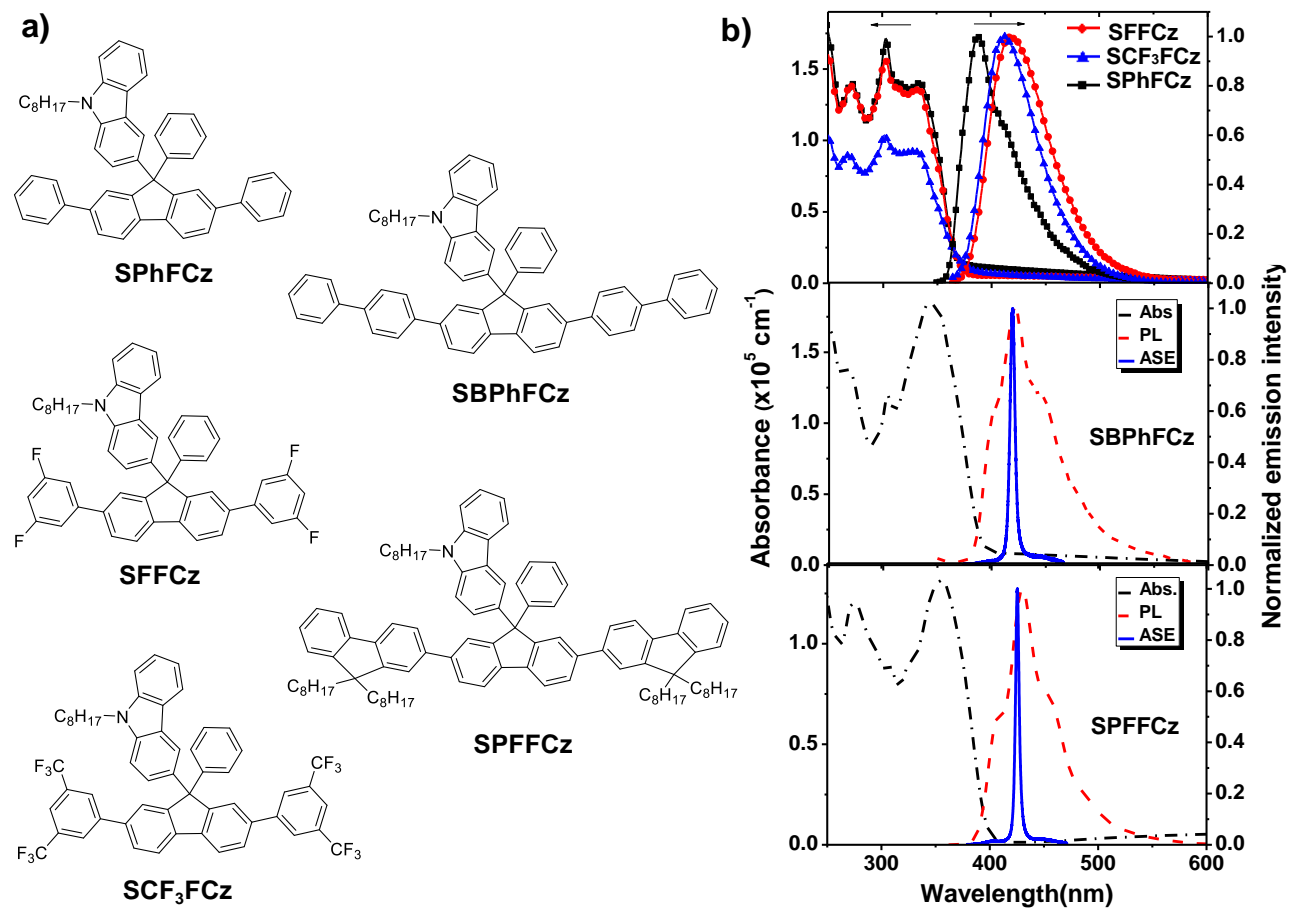
Figure 1. (a) Chemical structures; (b) Absorption, fluorescence, and ASE spectra of the carbazole substituted diarylfluorene compounds in films.

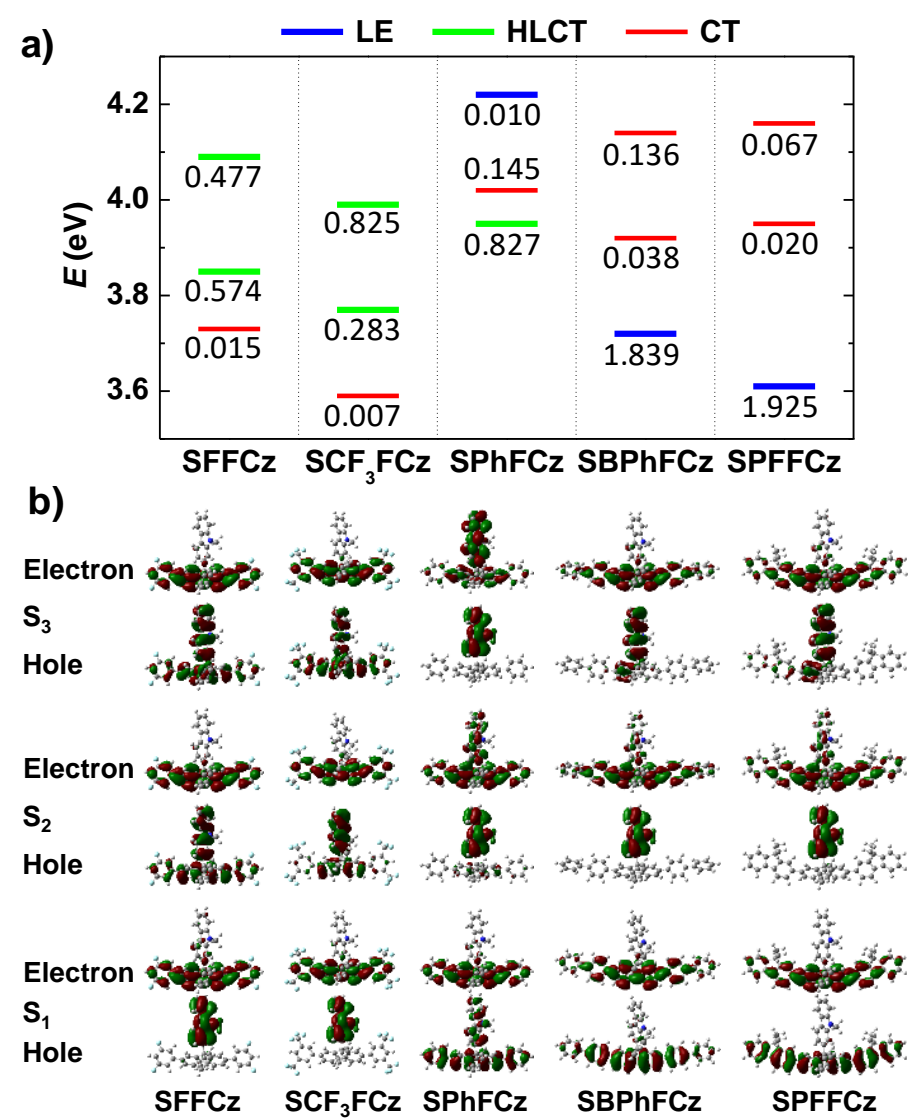

Figure 2. (a) Excitation energies, oscillator strengths (denoted below the energy levels), and main transition characters; (b) Natural transition orbitals for the lowest three singlet excited states $\left(\mathrm{S}_{1}, \mathrm{~S}_{2}\right.$, and $\left.\mathrm{S}_{3}\right)$. 
a)

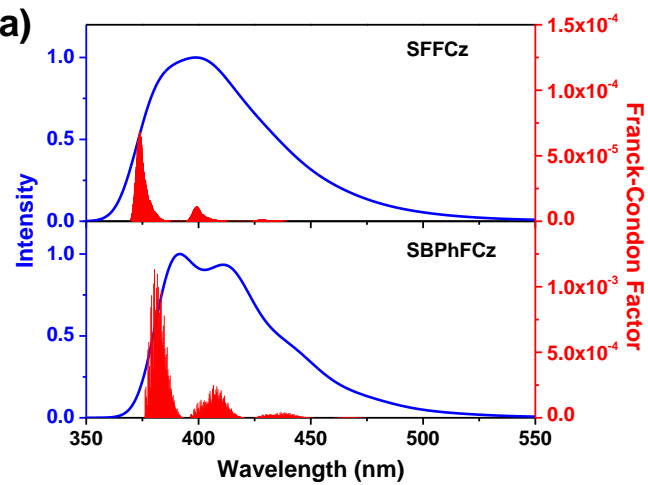

b)

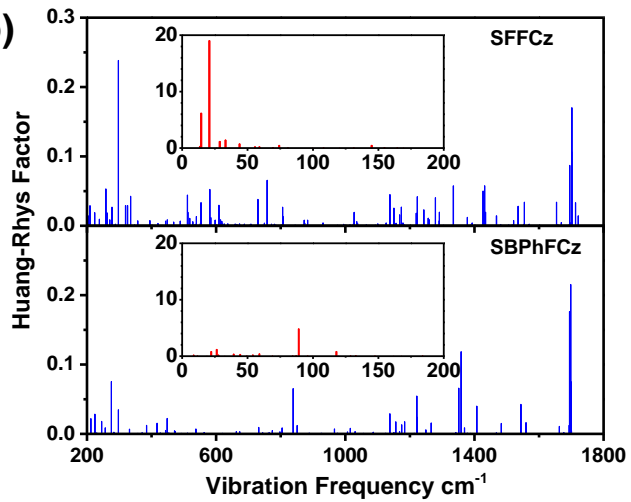

c)

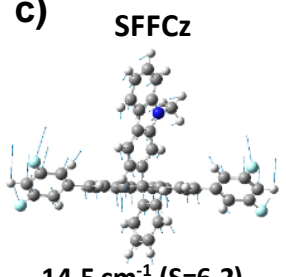

$14.5 \mathrm{~cm}^{-1}(\mathrm{~S}=6.2)$

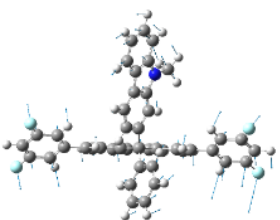

$20.8 \mathrm{~cm}^{-1}$ ( $\left.\mathrm{S}=19.0\right)$

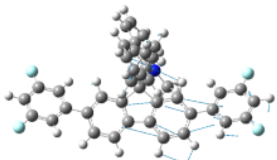

$1701.3 \mathrm{~cm}^{-1}$ (S=0.107)

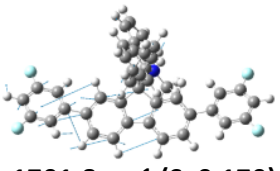

$1701.8 \mathrm{~cm}^{-1}(\mathrm{~S}=0.170)$

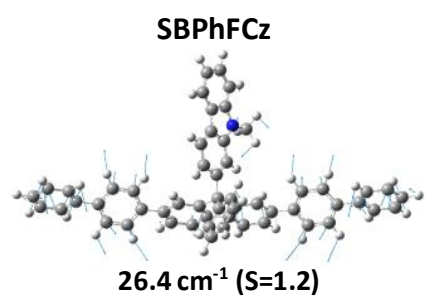

$26.4 \mathrm{~cm}^{-1}$ (S=1.2)

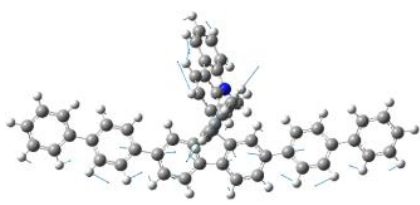

$89.1 \mathrm{~cm}^{-1}(\mathrm{~S}=4.8)$

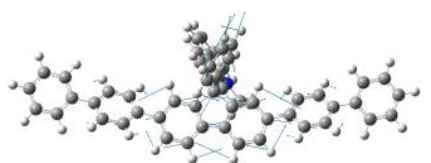

$1694.3 \mathrm{~cm}^{-1}$ ( $\left.\mathrm{S}=0.176\right)$

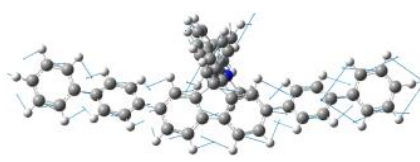

$1698.1 \mathrm{~cm}^{-1}(\mathrm{~S}=0.215)$

Figure 3. (a) Calculated fluorescence spectra and related multi-mode Franck-Condon factors; (b) Vibronic couplings (Huang-Rhys factors) for the $\mathrm{S}_{1} \rightarrow \mathrm{S}_{0}$ transition; (c) Illustration of the low-frequency $\left(<200 \mathrm{~cm}^{-1}\right)$ and high-frequency $\left(>200 \mathrm{~cm}^{-1}\right)$ vibration modes with the largest Huang-Rhys factors $(S)$ for the $\mathrm{S}_{1} \rightarrow \mathrm{S}_{0}$ transition in SFFCz and SBPhFCz.
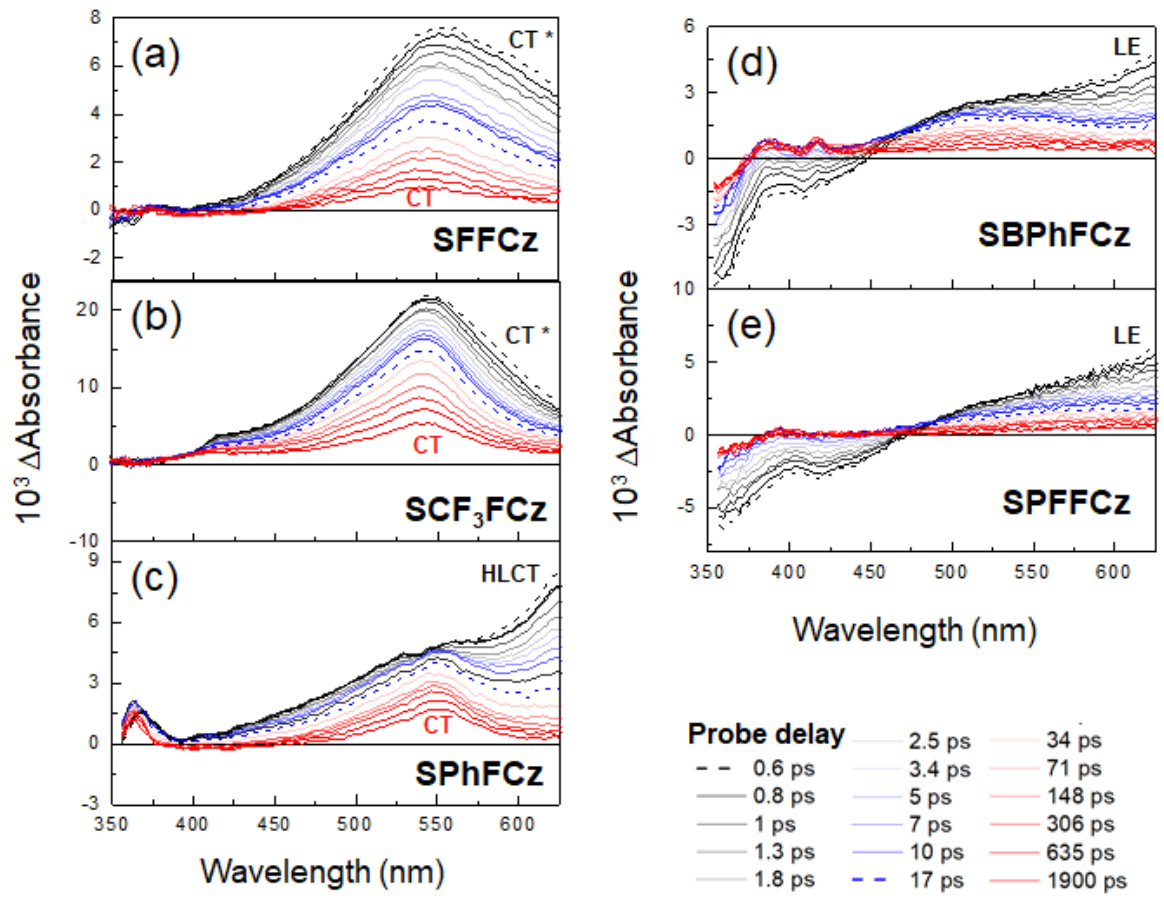

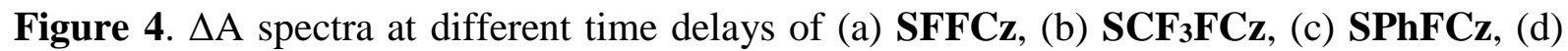
SBPhFCz, (e) SPFFCz in films. Note that only SPFFCz and SBPhFCz exhibit SE (displayed as negative $\Delta \mathrm{A}$ in the $400-475 \mathrm{~nm}$ spectral region). 
Table 1. The photophysical parameters of films

\begin{tabular}{lllll} 
Compound & $\begin{array}{l}\tau_{\mathrm{av}} \\
{[\mathrm{ns}]^{\mathrm{a})}}\end{array}$ & $\varphi_{\mathrm{f}}$ & $\begin{array}{l}\mathrm{k}_{\mathrm{r}} \\
{\left[10^{9} \mathrm{~ns}\right]}\end{array}$ & $\begin{array}{l}\mathrm{k}_{\mathrm{nr}} \\
{\left[10^{9} \mathrm{~ns}\right]}\end{array}$ \\
\hline $\mathrm{SFFCz}$ & 12.28 & $52 \%$ & 0.043 & 0.038 \\
$\mathrm{SCF}_{3} \mathrm{FCz}$ & 13.64 & $50 \%$ & 0.037 & 0.037 \\
$\mathrm{SPhFCz}$ & 2.06 & $39 \%$ & 0.189 & 0.296 \\
$\mathrm{SBPhFCz}$ & 0.76 & $47 \%$ & 0.618 & 0.697 \\
SPFFCz & 0.74 & $66 \%$ & 0.891 & 0.459 \\
\hline
\end{tabular}

a) the average lifetime of the fluorescence decay 
The intramolecular low-threshold ASE is highly correlated to the character of the lowest excited states. The pure local excited state favors ASE with discrete vibrational levels for efficient population inversion. The charge transfer state exhibit no ASE because its significant inter-fragment geometry change causes large vibronic coupling in the low-frequency region, difficult to form well-resolved vibrational energy levels.

Qi Wei ${ }^{\ddagger}$, Ruihong Duan ${ }^{\ddagger}$, Qi Zhang, Linghai Xie, Ruidong Xia, Yuanping Yi*, Jérémie Léonard, Stefan Haacke, Juan Cabanillas-Gonzalez*, Yan Qian*, and Wei Huang*

Origin of Intramolecular Low-Threshold Amplified Spontaneous Emission

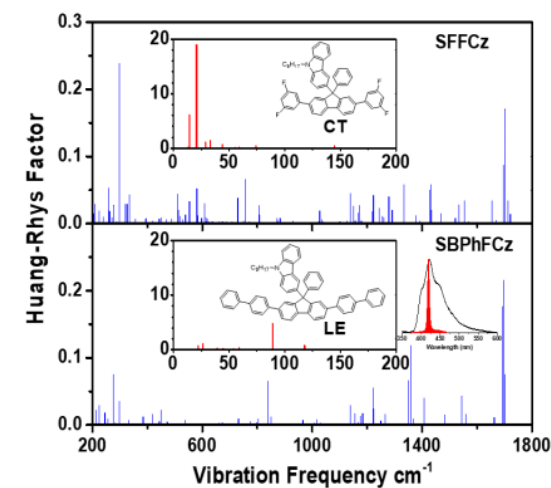


Copyright 2020. WILEY-VCH GmbH.

Supporting Information

Origin of Intramolecular Low-Threshold Amplified Spontaneous Emission

Qi Wei*, Ruihong Duan*, Qi Zhang, Linghai Xie, Ruidong Xia, Yuanping Yi*, Jérémie

Léonard, Stefan Haacke, Juan Cabanillas-Gonzalez*, Yan Qian*, and Wei Huang* 


\section{Synthesis of the carbazole substituted arylfluorenes}

Materials. Boron fluoride ethyl ether were purchased from Shangshai Ling Feng Chemical CO. Tetrakis(triphenylphosphine)palladium(0), 2,7-dibromo-9H-fluoren-9-one, (3,5-difluoro phenyl)boronic acid, (4-(trifluoromethyl)phenyl)boronic acid and [1,1'-biphenyl]-4-ylboronic acid were purchased from Aldrich Chemical Co. The tertiary alcohols of 2,7-aryl-substituted 9-phenyl-9H-fluoren-9-ol were synthesized by Suzuki coupling of 2,7-dibromo-9-phenyl-9Hfluoren-9-ol with different various brominated aryls.
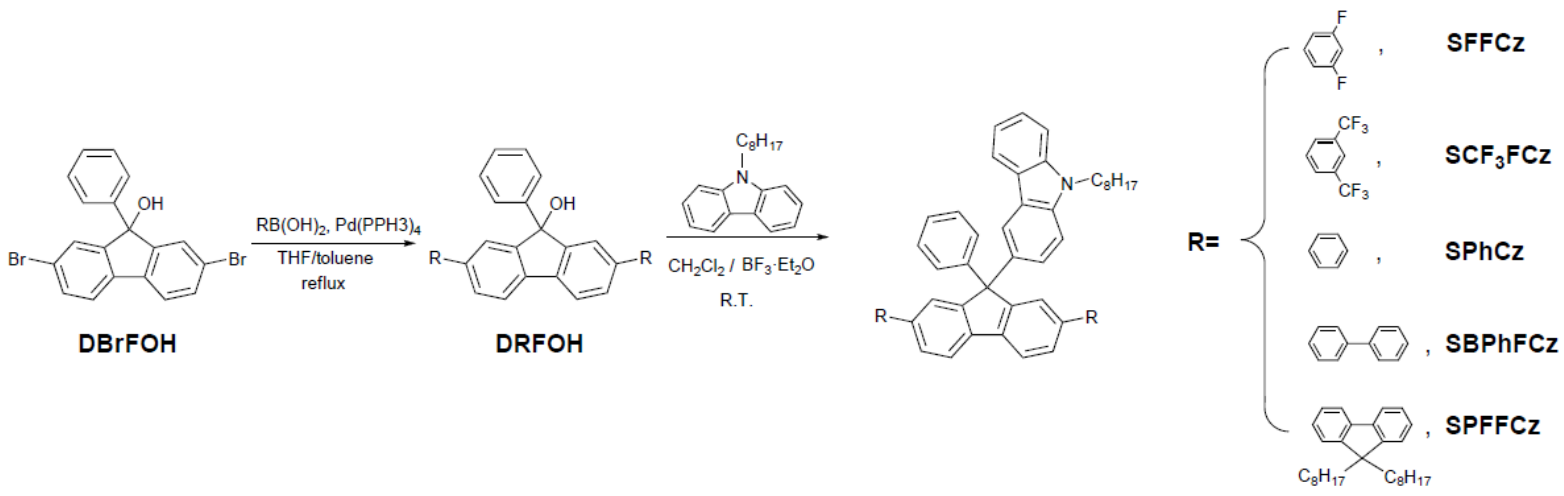

Scheme S1. The synthetic routes of the carbazole substituted 9-phenyldiarylfluorene.

Synthesis of 3-(2,7-bis(3,5-difluorophenyl)-9-phenyl-9H-fluoren-9-yl)-9-octyl-9Hcarbazole ( $\mathrm{SFFCz})$

$\mathrm{BF}_{3} \cdot \mathrm{Et}_{2} \mathrm{O}(1.3 \mathrm{ml}, 9.16 \mathrm{mmol})$ was added to anhydrous $\mathrm{CH}_{2} \mathrm{Cl}_{2}(100 \mathrm{ml}$

) solution of DRFOH (1.0 g, $2.1 \mathrm{mmol})$ and 9-octyl-9H-carbazole (0.56 g, $2.0 \mathrm{mmol})$, and the batch was stirred over a period of $5 \mathrm{~h}$ at room temperature. The resulting mixture was washed by water and extracted with $\mathrm{CH}_{2} \mathrm{Cl}_{2}$. The residue then subjected to silica-gel column chromatography to afford $0.44 \mathrm{~g}$ white solid of $\mathrm{SFFCz}$ in $30 \%$ yield. ${ }^{1} \mathrm{H}$ NMR $(400 \mathrm{MHz}$, $\left.\mathrm{CDCl}_{3}\right) \delta$ 7.94-7.92 (m, 2H), 7.91-7.89 (d, J=8.0 Hz, 2H), $7.66(\mathrm{~s}, 2 \mathrm{H}), 7.61-7.58(\mathrm{~d}, J=7.9$, 2H), 7.45-7.33 (m, 5H), 7.33-7.26 (m, 4H),7.16-7.13 (t, $J=7.4 \mathrm{~Hz}, 1 \mathrm{H}), 7.08-7.06(\mathrm{~d}, J=8.5$ $\mathrm{Hz}, 4 \mathrm{H}), 6.77-6.72(\mathrm{t}, J=8.8 \mathrm{~Hz}, 2 \mathrm{H}), 4.26-4.22(\mathrm{t}, J=7.3 \mathrm{~Hz}, 2 \mathrm{H}), 1.89-1.79(\mathrm{~m}, 2 \mathrm{H}), 1.42-$ $1.18(\mathrm{~m}, 10 \mathrm{H}), 0.86-0.83(\mathrm{t}, J=6.7 \mathrm{~Hz}, 3 \mathrm{H}) .{ }^{13} \mathrm{C} \mathrm{NMR}\left(400 \mathrm{MHz}, \mathrm{CDCl}_{3}\right) \delta 164.56,164.43$, $162.10,161.97,153.44,146.08,144.55,140.80,139.80,139.45,138.74,128.52,128.21$, 
$126.95,126.68,126.18,125.72,124.95,120.96,120.40,119.51,118.73,110.09,109.84$, $108.77,108.71,102.69,102.44,102.18,65.88,43.19,31.78,29.34,29.16,29.03,27.32,22.59$, 14.05. MALDI-TOF m/z: 743.69 [M]. Anal. Calcd. for $\mathrm{C}_{51} \mathrm{H}_{41} \mathrm{~F}_{4} \mathrm{~N}$ (743.32): C, 82.35; H, 5.56; N, 1.88\%; found: C, 82.48; H, 5.68; N, $1.67 \%$.

\section{Synthesis of 3-(2,7-bis(3,5-bis(trifluoromethyl)phenyl)-9-phenyl-9H-fluoren-9-yl)-9- octyl-9H- carbazole $\left(\mathrm{SCF}_{3} \mathrm{FCz}\right)$}

$\mathrm{BF}_{3} \cdot \mathrm{Et}_{2} \mathrm{O}(1.3 \mathrm{ml}, 9.16 \mathrm{mmol})$ was added to anhydrous $\mathrm{CH}_{2} \mathrm{Cl}_{2}(100 \mathrm{ml})$ solution of DRFOH $(0.9 \mathrm{~g}, 1.4 \mathrm{mmol})$ and 9-octyl-9H-carbazole $(2.2 \mathrm{~g}, 1.2 \mathrm{mmol})$, and the batch was stirred over a period of $5 \mathrm{~h}$ at room temperature. The resulting mixture was washed by water and extracted with $\mathrm{CH}_{2} \mathrm{Cl}_{2}$. The residue then subjected to silica-gel column chromatography to afford $0.51 \mathrm{~g}$ white solid of $\mathrm{SCF}_{3} \mathrm{FCz}$ in $45 \%$ yield. $\mathrm{SCF}_{3} \mathrm{FCz}$ : ${ }^{1} \mathrm{H} \mathrm{NMR}\left(400 \mathrm{MHz}, \mathrm{CDCl}_{3}\right) \delta$ 7.99-7.97 (d, $J=7.9 \mathrm{~Hz}, 2 \mathrm{H}), 7.95(\mathrm{~s}, 5 \mathrm{H}), 7.93-9.91(\mathrm{~d}, J=7.8 \mathrm{~Hz}, 1 \mathrm{H}), 7.82(\mathrm{~s}, 2 \mathrm{H}), 7.68(\mathrm{~s}, 2 \mathrm{H}), 7.67-$ $7.65(\mathrm{~d}, J=7.9 \mathrm{~Hz}, 2 \mathrm{H}), 7.41-7.39(\mathrm{~d}, J=7.9 \mathrm{~Hz}, 4 \mathrm{H}), 7.36-7.32(\mathrm{~m}, 5 \mathrm{H}), 7.16-7.12(\mathrm{t}, J=7.4$ $\mathrm{Hz}, 1 \mathrm{H}), 4.26-4.22(\mathrm{t}, 7.3 \mathrm{~Hz}, 2 \mathrm{H}), 1.85-1.79(\mathrm{~m}, 2 \mathrm{H}), 1.38-1.15(\mathrm{~m}, 10 \mathrm{H}), 0.86-0.82(\mathrm{t}, J=$ $6.8 \mathrm{~Hz}, 3 \mathrm{H}) .{ }^{13} \mathrm{C}$ NMR $\left(400 \mathrm{MHz}, \mathrm{CDCl}_{3}\right) \delta 153.90,145.41,143.26,139.89,139.86,138.33$, $135.15,132.52,132.19,131.86,131.53,128.64,128.05,127.39,127.22,127.07,126.39$, $125.00,124.67,122.52,121.96,121.32,120.88,119.56,119.25,108.98,66.07,43.25,31.70$, 29.25, 29.06, 28.98, 27.25, 22.49, 13.96. MALDI-TOF m/z: 943.54 [M]. Anal. Calcd. for $\mathrm{C}_{55} \mathrm{H}_{41} \mathrm{~F}_{12} \mathrm{~N}$ (943.30): C, 69.98; H, 4.38; N, 1.48\%; found: C, 69.78; H, 4.58; N, $1.38 \%$.

\section{Synthesis of 9-octyl-3-(2,7,9-triphenyl-9H-fluoren-9-yl)-9H-carbazole (SPhFCz)}

$\mathrm{BF}_{3} \cdot \mathrm{Et}_{2} \mathrm{O}(1.3 \mathrm{ml}, 9.16 \mathrm{mmol})$ was added to anhydrous $\mathrm{CH}_{2} \mathrm{Cl}_{2}(100 \mathrm{ml})$ solution of DRFOH $(1.0 \mathrm{~g}, 2.4 \mathrm{mmol})$ and 9-octyl-9H-carbazole $(0.62 \mathrm{~g}, 2.2 \mathrm{mmol})$, and the batch was stirred over a period of $5 \mathrm{~h}$ at room temperature. The resulting mixture was washed by water and extracted with $\mathrm{CH}_{2} \mathrm{Cl}_{2}$. The residue then subjected to silica-gel column chromatography to afford $0.46 \mathrm{~g}$

white solid of SPhFCz in $31 \%$ yield. ${ }^{1} \mathrm{H}$ NMR $\left(400 \mathrm{MHz}, \mathrm{CDCl}_{3}\right) \delta 8.0(\mathrm{~s}, 1 \mathrm{H}), 7.95-7.91$ (d, 
$J=7.7 \mathrm{~Hz}, 1 \mathrm{H}), 7.90-7.88(\mathrm{~d}, J=7.9 \mathrm{~Hz}, 2 \mathrm{H}), 7.73(\mathrm{~s}, 2 \mathrm{H}), 7.65-7.63(\mathrm{~d}, J=7.9 \mathrm{~Hz}, 2 \mathrm{H}), 7.58-$ $7.56(\mathrm{~d}, J=7.4 \mathrm{~Hz}, 4 \mathrm{H}), 7.43-7.20(\mathrm{~m}, 15 \mathrm{H}), 7.16-7.12(\mathrm{t}, J=7.3 \mathrm{~Hz}, 1 \mathrm{H}), 4.25-4.22(\mathrm{t}, J=7.2$ $\mathrm{Hz}, 2 \mathrm{H}), 1.87-1.78(\mathrm{~m}, 2 \mathrm{H}), 1.38-1.22(\mathrm{~m}, 10 \mathrm{H}), 0.86-0.83(\mathrm{t}, \mathrm{J}=7.2 \mathrm{~Hz}, 3 \mathrm{H}) .{ }^{13} \mathrm{C}$ NMR (400 $\left.\mathrm{MHz}, \mathrm{CDCl}_{3}\right) \delta 152.98,146.68,141.40,140.75,139.35,139.05,136.12,128.72,128.36$, $128.33,127.20,127.17,126.69,126.64,126.42,125.53,125.14,122.75,122.58,120.52$, $120.45,119.70,118.57,108.60 .65 .80,43.17,31.80,29.36,29.17,29.03,27.33,22.60,14.09$. MALDI-TOF m/z: $673.13[\mathrm{M}+2 \mathrm{H}]^{+}$. Anal. Calcd. for $\mathrm{C}_{51} \mathrm{H}_{45} \mathrm{~N}$ (671.36): C, 91.16; H, 6.75; N, $2.08 \%$; found: C, $91.35 ; \mathrm{H}, 6.64 ; \mathrm{N}, 2.38 \%$.

Synthesis of 3-(2,7-di([1,1'-biphenyl]-4-yl)-9-phenyl-9H-fluoren-9-yl)-9-octyl-9Hcarbazole (SBPhFCz)

$\mathrm{BF}_{3} \cdot \mathrm{Et}_{2} \mathrm{O}(1.3 \mathrm{ml}, 9.16 \mathrm{mmol})$ was added to anhydrous $\mathrm{CH}_{2} \mathrm{Cl}_{2}(100 \mathrm{ml})$ solution of DRFOH $(1.0 \mathrm{~g}, 1.8 \mathrm{mmol})$ and 9-octyl-9H-carbazole $(0.48 \mathrm{~g}, 1.7 \mathrm{mmol})$, and the batch was stirred over a period of $5 \mathrm{~h}$ at room temperature. The resulting mixture was washed by water and extracted with $\mathrm{CH}_{2} \mathrm{Cl}_{2}$. The residue then subjected to silica-gel column chromatography to afford $0.53 \mathrm{~g}$ white solid of $\mathrm{SBPhCz}$ in $38 \%$ yield. ${ }^{1} \mathrm{H}$ NMR $\left(400 \mathrm{MHz}, \mathrm{CDCl}_{3}\right) \delta 8.02(\mathrm{~s}, 1 \mathrm{H}), 7.96-7.94(\mathrm{~d}$, $J=7.7 \mathrm{~Hz}, 1 \mathrm{H}), 7.92-7.90(\mathrm{~d}, J=7.9 \mathrm{~Hz}, 2 \mathrm{H}), 7.78(\mathrm{~s}, 2 \mathrm{H}), 7.71-7.61(\mathrm{~m}, 14 \mathrm{H}), 7.48-7.27(\mathrm{~m}$, $15 \mathrm{H}), 7.16-7.12(\mathrm{t}, J=7.3 \mathrm{~Hz}, 1 \mathrm{H}), 4.26-4.22(\mathrm{t}, J=7.3 \mathrm{~Hz}, 2 \mathrm{H}), 1.88-1.82(\mathrm{~m}, 2 \mathrm{H}), 1.37-1.22$ $(\mathrm{m}, 10 \mathrm{H}), 0.86-0.82(\mathrm{t}, J=6.8 \mathrm{~Hz}, 3 \mathrm{H}) .{ }^{13} \mathrm{C} \mathrm{NMR}\left(400 \mathrm{MHz}, \mathrm{CDCl}_{3}\right) \delta 153.08,146.65$, $140.78,140.72,140.29,140.24,140.05,139.39,139.15,136.10,128.80,128.38,127.54$ $127.46,127.31,127.03,126.67,126.59,126.42,125.55,125.02,122.76,122.62,120.60$, $120.46,119.72,118.60,108.63,65.84,43.18,31.79,29.36,29.17,29.03,27.33,22.59,14.07$. MALDI-TOF m/z: 823.35 [M]. Anal. Calcd. for $\mathrm{C}_{63} \mathrm{H}_{53} \mathrm{~N}$ (823.42): C, 91.82; H, 6.48; N, $1.70 \%$; found: $\mathrm{C}, 91.64 ; \mathrm{H}, 6.35 ; \mathrm{N}, 1.82 \%$. 
Synthesis of 3-(2,7-di([1,1'-biphenyl]-4-yl)-9-phenyl-9H-fluoren-9-yl)-9-octyl-9Hcarbazole (SBPhFCz)

$\mathrm{BF}_{3} \cdot \mathrm{Et}_{2} \mathrm{O}(1.3 \mathrm{ml}, 9.16 \mathrm{mmol})$ was added to anhydrous $\mathrm{CH}_{2} \mathrm{Cl}_{2}(100 \mathrm{ml})$ solution of DRFOH (2.48 g, $2.4 \mathrm{mmol})$ and 9-octyl-9H-carbazole (0.62 g, $2.2 \mathrm{mmol})$, and the batch was stirred over a period of $5 \mathrm{~h}$ at room temperature. The resulting mixture was washed by water and extracted with $\mathrm{CH}_{2} \mathrm{Cl}_{2}$. The residue then subjected to silica-gel column chromatography to afford $2.08 \mathrm{~g}$ white solid in $73 \%$ yield. ${ }^{1} \mathrm{H} \mathrm{NMR}\left(400 \mathrm{MHz}, \mathrm{CDCl}_{3}\right) \delta 8.08(\mathrm{~s}, 1 \mathrm{H}), 7.98-7.94$ (d, $J=7.8 \mathrm{~Hz}, 1 \mathrm{H}), 7.94-7.90(\mathrm{~d}, J=7.9 \mathrm{~Hz}, 2 \mathrm{H}), 7.80(\mathrm{~s}, 2 \mathrm{H}), 7.74-7.65(\mathrm{~m}, 6 \mathrm{H}), 7.55(\mathrm{~s}$, 1H), $7.53(\mathrm{~s}, 3 \mathrm{H}), 7.50-7.27(\mathrm{~m}, 15 \mathrm{H}), 7.16-7.11(\mathrm{t}, J=7.1 \mathrm{~Hz}, 1 \mathrm{H}), 4.28-4.20(\mathrm{t}, J=7.2 \mathrm{~Hz}$, 2H), 2.03-1.90 (t, $J=7.2 \mathrm{~Hz}, 8 \mathrm{H}), 1.88-1.78(\mathrm{~m}, 2 \mathrm{H}), 1.42-0.96(\mathrm{~m}, 50 \mathrm{H}), 0.87-0.74(\mathrm{~m}$, 15H), 0.73-0.55 (m, 8H). ${ }^{13} \mathrm{C}$ NMR (400 MHz, $\left.\mathrm{CDCl}_{3}\right) \delta 152.99,151.40,151.03,146.89$, $141.26,140.82,140.76,140.37,140.19,139.40,138.97,136.18,128.44,128.40,126.98$, $126.80,126.76,126.69,126.46,126.10,125.62,125.03,122.90,122.77,122.70,121.37$, $120.46,120.43,119.85,119.80,119.71,118.70,108.64,108.60,65.89,55.15,43.22,40.37$, $31.82,31.78,30.07,30.05,29.75,29.38,29.25,29.23,29.22,29.19,29.07,27.36,23.81$, 22.61, 14.10. MALDI-TOF m/z: $1295.58[\mathrm{M}]^{+}$. Anal. Calcd. for $\mathrm{C}_{97} \mathrm{H}_{117} \mathrm{~N}$ (1295.92): C, 89.83; H, 9.09; N, 1.08\%; found: C, 89.75; H, 9.30; N, $1.12 \%$.

Synthesis of 9-octyl-3-(9,9,9",9"'-tetraoctyl-9'-phenyl-9H,9'H,9' 'H-[2,2':7',2' '-terfluoren] -9'-yl)-9H-carbazole (SPFFCz)

The synthesis and characterization of SPFFCz has been described in detail in our previously reported publication. ${ }^{[1]}$ 


\section{Thermal Stabilities}

\subsection{Tg Curves}
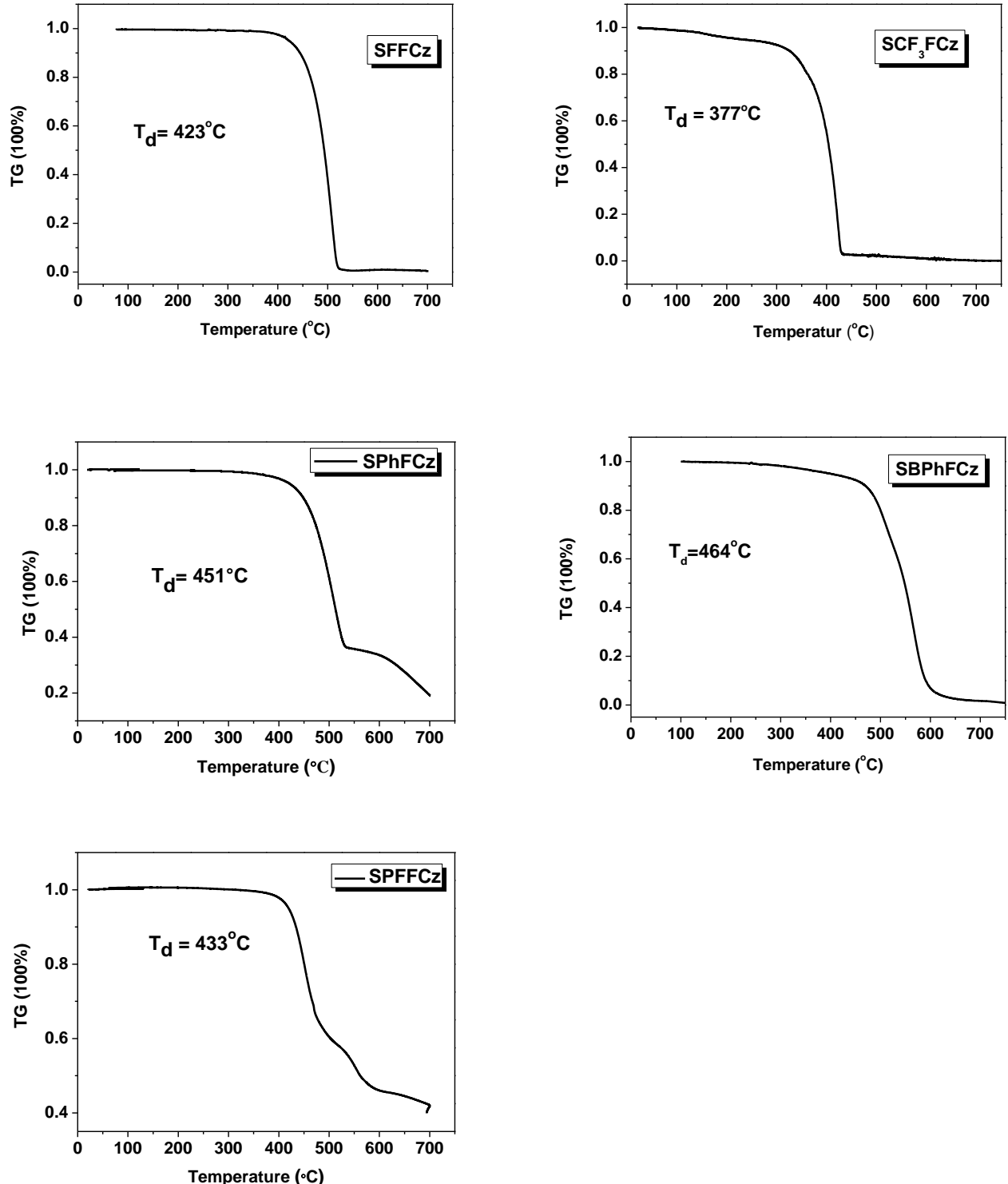

Figure S1. TG curves of of the carbazole substituted arylfluorenes. 


\subsection{DSC curves}
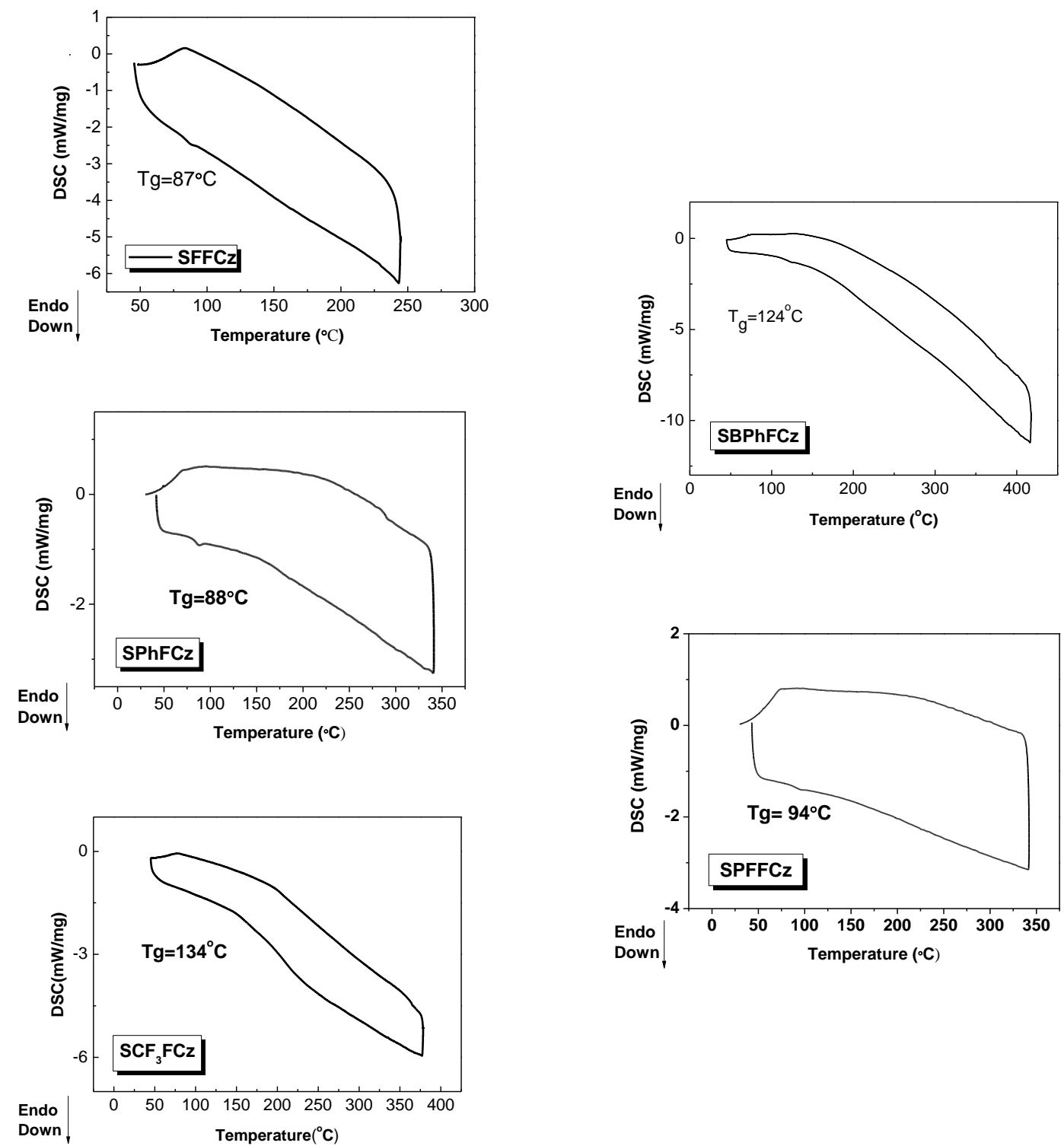

Figure S2. DSC curves (the third cycle) of the carbazole substituted arylfluorenes. 


\section{Normalized absorption and fluorescence spectra in solution}
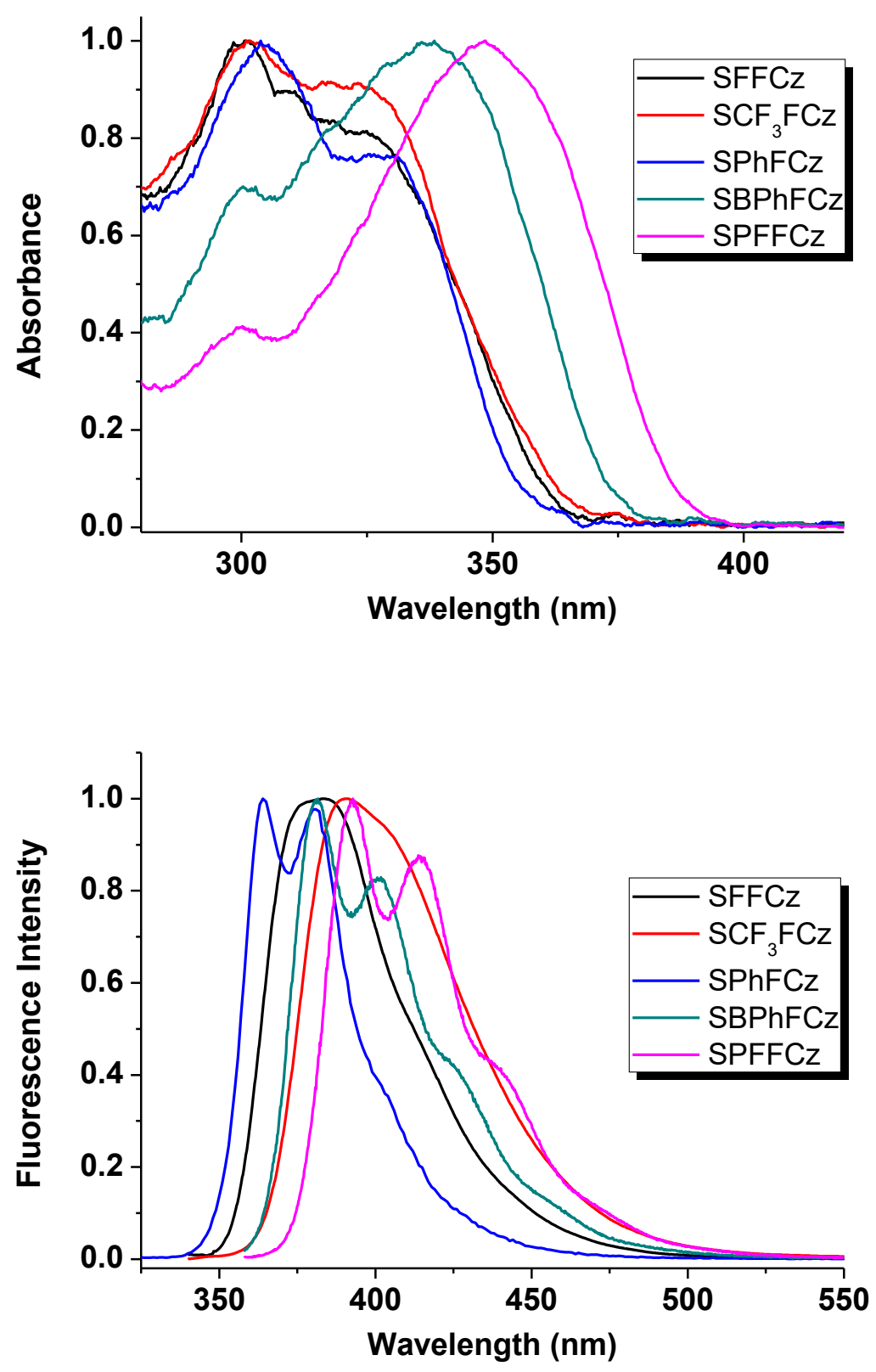

Figure S3. Normalized absorption and fluorescence spectra of the carbazole substituted arylfluorenes in $n$-hexane $\left(1 \times 10^{-5} \mathrm{~mol} / \mathrm{L}\right)$. 


\section{PL decay spectra of films}

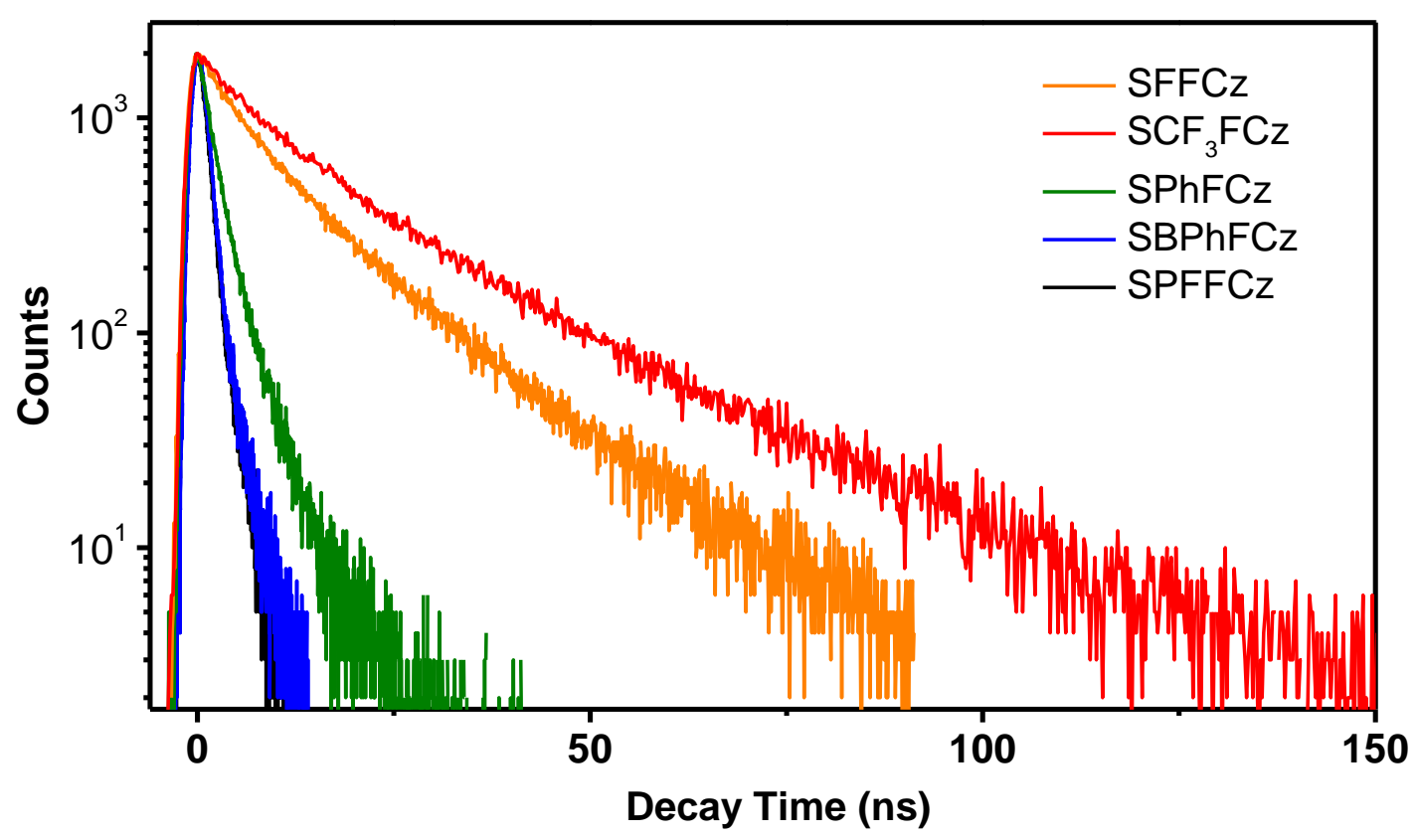

Figure S4. PL decay spectra of films (excited at $375 \mathrm{~nm}$, and detected at their maximum emission wavelengths).

Table S1. PL lifetime parameters in the films

\begin{tabular}{lllll}
\hline & $\begin{array}{l}\tau_{1} \\
{[\mathrm{~ns}]}\end{array}$ & $\begin{array}{l}\tau_{2} \\
{[\mathrm{~ns}]}\end{array}$ & $\begin{array}{l}<\tau_{\text {av }} \\
{[\mathrm{ns}]^{\mathrm{a}}}\end{array}$ & $\mathrm{x}^{2}$ \\
\hline $\mathrm{SFFCz}$ & $5.48(30.88 \%)$ & $15.33(69.12 \%)$ & 12.28 & 1.073 \\
$\mathrm{SCF}_{3} \mathrm{FCz}$ & $6.24(34.56 \%)$ & $17.55(65.44 \%)$ & 13.64 & 0.929 \\
$\mathrm{SPhFCz}$ & $1.17(62.13 \%)$ & $3.52(37.87 \%)$ & 2.06 & 1.129 \\
$\mathrm{SBPhFCz}$ & 0.76 & - & 0.76 & 1.148 \\
$\mathrm{SPFFCz}$ & 0.74 & - & 0.74 & 1.214 \\
\hline
\end{tabular}

a) the average lifetime 


\section{Solvent-dependent Fluorescence Spectra}
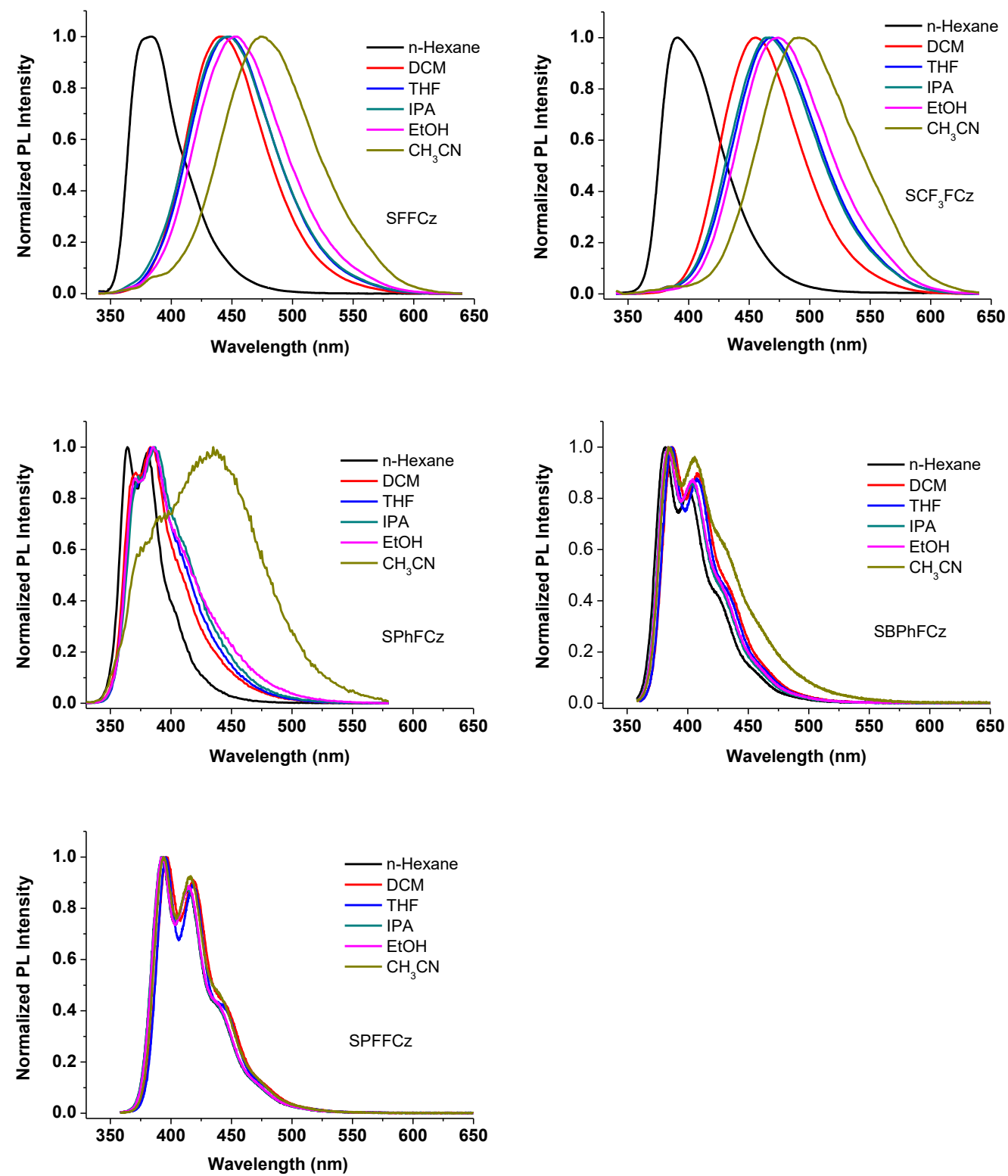

Figure S5. Solvent-dependent fluorescence spectra of the carbazole substituted arylfluorenes $\left(1 \times 10^{-5} \mathrm{~mol} / \mathrm{L}\right)$. 


\section{Theoretical calculations}

Computational details. The molecular geometries were optimized by density functional theory (DFT) for the ground state $\left(\mathrm{S}_{0}\right)$ and by time-dependent DFT (TDDFT) for the lowest singlet excited state $\left(\mathrm{S}_{1}\right)$ at the MPW1B95/6-31G(d,p) level, which can well reproduce the experimental maximum absorption wavelengths (see Table S2). For simplification, all the octyl groups were replaced by methyl for the five studied molecules in the calculations. All the DFT/TDDFT calculations were carried out by Gaussian 09 program. ${ }^{[2]}$ Natural transition orbitals (NTOs) were obtained for the excitation from the ground state to the lowest three excited states to examine their transition nature. Based on the optimized $S_{0}$ and $S_{1}$ geometries and vibration modes, the vibronic couplings, namely Huang-Rhys factors were calculated and the fluorescence spectra were obtained by the thermal vibration correlation function (TVCF) method, as implemented in the MOMAP program. ${ }^{[3]}$

Table S2. Vertical excitation energies of $S_{1}, S_{2}$, and $S_{3}$ for the studied compounds calculated by TDDFT. For the strong absorbing states, the absorption wavelength are listd in brackets.

\begin{tabular}{|c|c|c|c|c|c|c|}
\hline \multirow{2}{*}{ Compound } & \multicolumn{2}{|c|}{$S_{1}$} & \multicolumn{2}{|c|}{$\mathrm{S}_{2}$} & \multicolumn{2}{|c|}{$\mathrm{S}_{3}$} \\
\hline & $E(\mathrm{eV})$ & $f$ & $E(\mathrm{eV})$ & $f$ & $E(\mathrm{eV})$ & $f$ \\
\hline SFFCz & 3.78 & 0.018 & $3.89(319 \mathrm{~nm})$ & 0.599 & $4.09(303 \mathrm{~nm})$ & 0.477 \\
\hline $\mathrm{SCF}_{3} \mathrm{FCz}$ & 3.59 & 0.007 & 3.77 & 0.283 & $3.99(311 \mathrm{~nm})$ & 0.825 \\
\hline SPhFCz & $3.95(314 \mathrm{~nm})$ & 0.827 & 4.02 & 0.145 & 4.22 & 0.010 \\
\hline SBPhFCz & $3.72(333 \mathrm{~nm})$ & 1.839 & 3.92 & 0.038 & 4.14 & 0.136 \\
\hline SPFFCz & $3.61(343 \mathrm{~nm})$ & 1.925 & 3.95 & 0.020 & 4.16 & 0.067 \\
\hline
\end{tabular}


Based on the Fermi golden rule and Condon's approximation, the fluorescence spectra can be expressed as ${ }^{[4]}$ :

$$
\sigma_{\text {fluo }}(\omega, T)=\frac{4 \omega^{3}}{3 \hbar c^{3}}\left|\mu_{\mathrm{fi}}\right|^{2} \sum_{v_{i}, v_{f}} P_{i v_{i}}(T)\left|<\Theta_{f, v_{f}}\right| \Theta_{i, v_{i}}>\left.\right|^{2} \delta\left(\omega_{i, v_{i}, f v_{i}}-\omega\right)
$$

Here, $P_{i v_{i}}(T)$ is the Boltzmann distribution of the vibration modes at the initial state $\mathrm{S}_{1}, \mu_{\mathrm{fi}}$ is the transition dipole moment for the fluorescence process. $v_{i} / v_{f}$ is vibrational quantum number of state $S_{1} / S_{0}, \Theta_{f, v_{f}} / \Theta_{i, v_{i}}$ is the vibrational wavefunction manifold of the state $S_{1} / S_{0}$, $\omega$ is the frequency, $\omega_{i, v_{i}, f v_{i}}=\omega_{i, v_{i}}-\omega_{f v_{i}}$ is the energy difference between the initial and finial vibronic states, respectively.

The shape of PL spectrum is mainly determined by the vibrational transition probability. For the $i$-th mode, when the initial vibrational level is 0 , its transition probability to vibrational level $v$ at ground state can be expressed as:

$$
\left|<0_{i, e}\right| v_{i, g}>\left.\right|^{2}=\frac{s_{i}^{n}}{v !} e^{-S_{\mathrm{i}}}
$$

Which is also called Franck-Condon factor, and here $S_{i}$ is Huang-Rhys factor, which represents the vibronic coupling strength:

$$
S_{i}=\frac{\omega\left(\Delta Q_{i}\right)^{2}}{2 \hbar}
$$

And $\Delta Q_{\mathrm{i}}$ represents the displacement along the normal mode $(\mathrm{NM})_{\mathrm{i}}$ between the equilibrium positions of the two electronic states.

For the high-frequency vibration modes, the vibronic couplings are generally weak, such as the largest couplings 0.170 and 0.215 for SFFCz and SBPhFCz, respectively. In weak coupling case $(S<1)$, the $0-1$ transition probability increase with the coupling increasing. Here the 0-1 transition for SBPhFCz is just slightly stronger than SFFCz (see Figure S6) due to the slightly larger vibronic coupling. For the low-frequency modes, the vibronic couplings could be very strong, such as the largest couplings 19.0 and 4.84 for $\mathbf{S F F C z}$ and $\mathbf{S B P h F C z}$ 
respectively. In strong coupling case $(S>1)$, the most probable transition is the 0 -Round(S) transition.
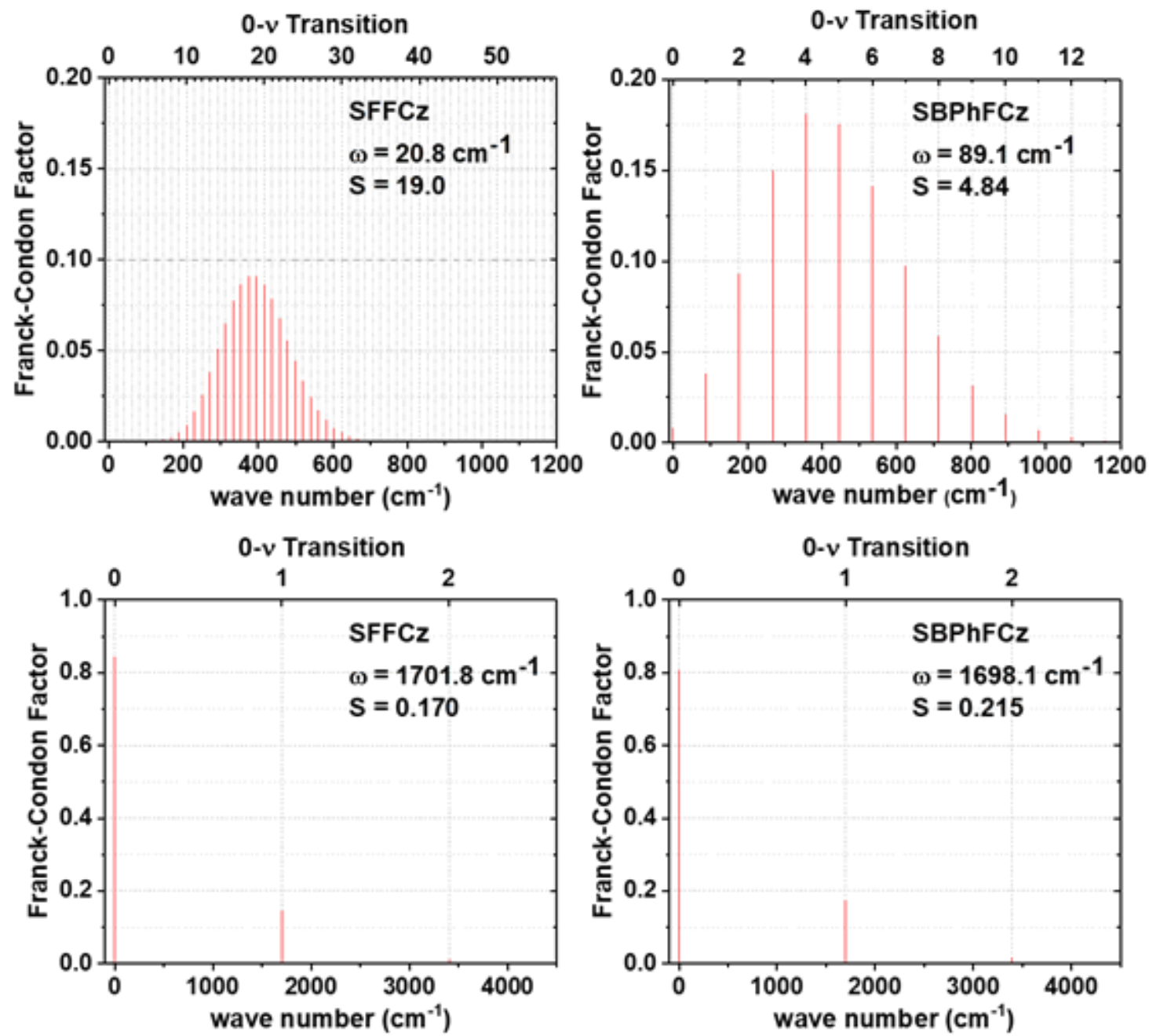

Figure S6. The single-mode Franck-Condon factor of the $0-v$ transition with the most representative vibrational mode (mode with the largest $S$ ) in low- and high-frequency region for SFFCz and SBPhFCz, respectively. 

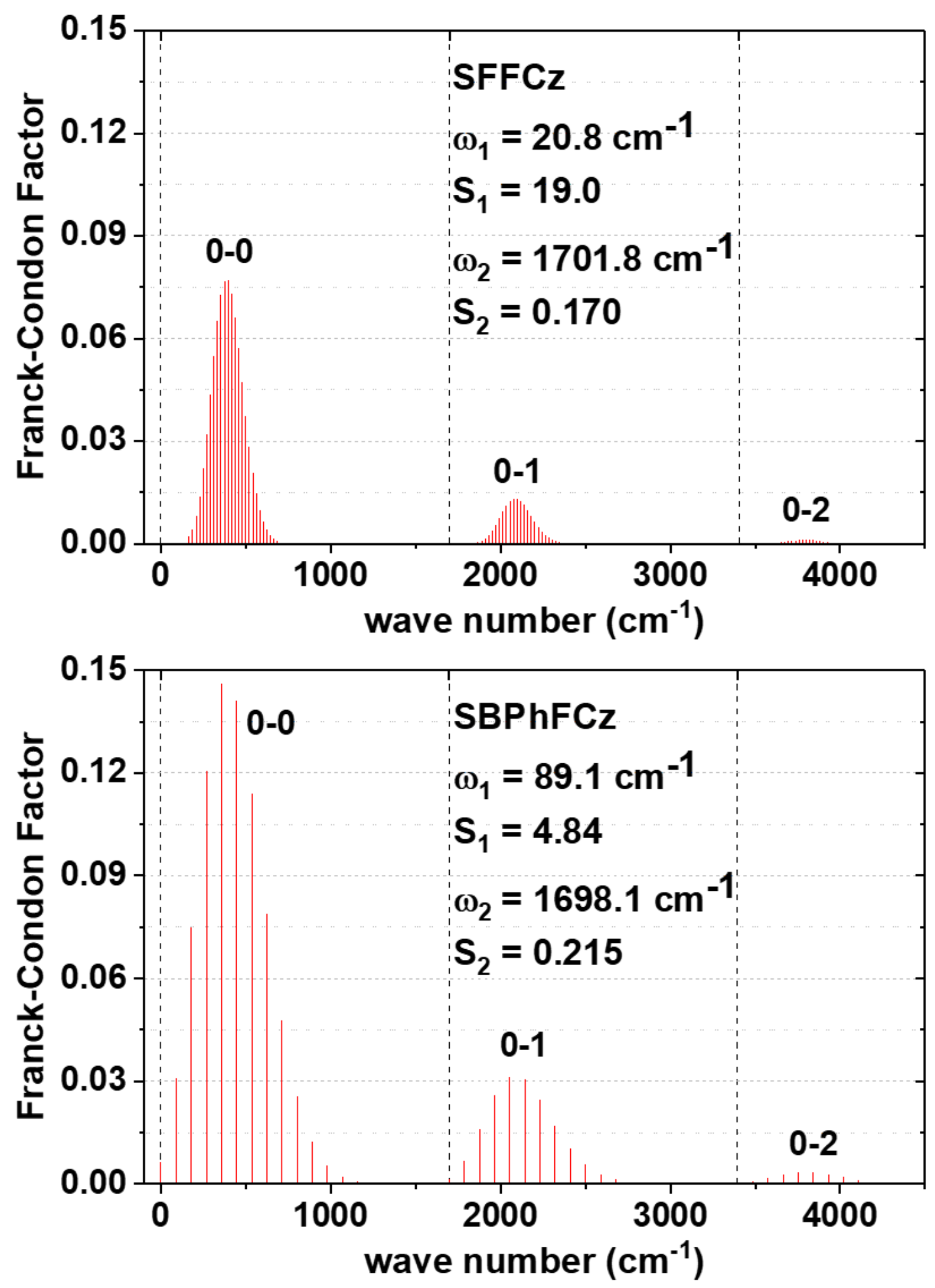

Figure S7. The double-mode Franck-Condon factor for $\mathbf{S F F C z}$ and $\mathbf{S B P h F C z}$, the most representative vibrational mode (with the largest $S$ ) in low- and high-frequency region are selected and the ' $0-v$ ' written in the figure is for the high-frequency mode. 

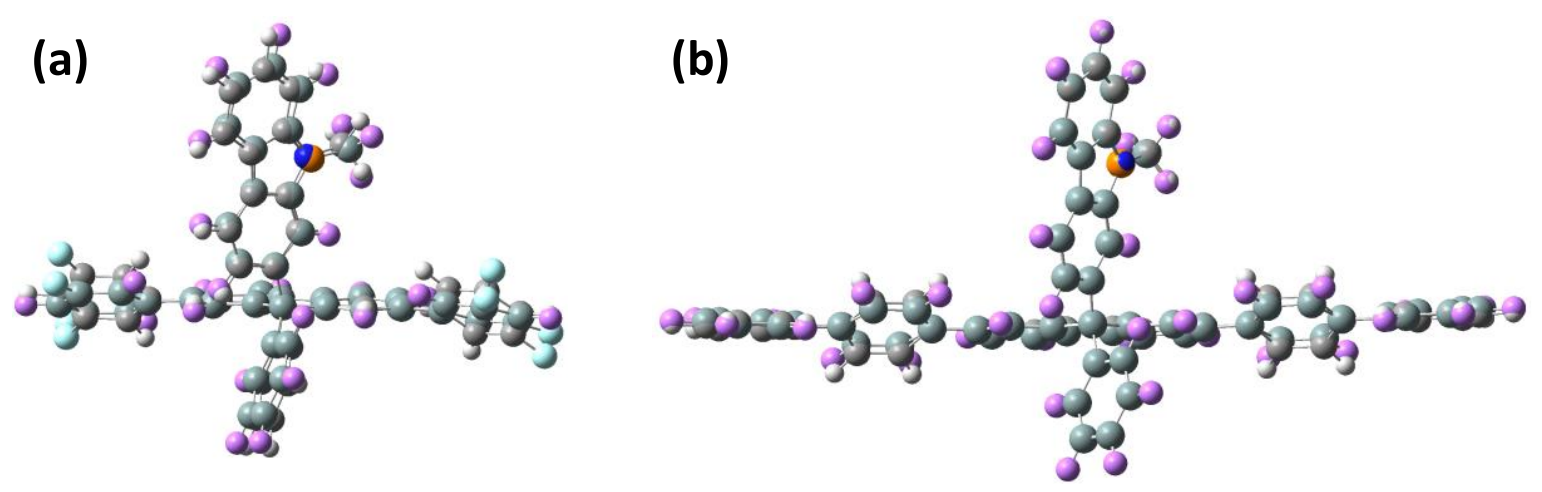

Figure S8. Comparison of the optimized structures between the $\mathrm{S}_{0}$ (in gray) and $\mathrm{S}_{1}$ (in purple) states for (a) SFFCz and (b) SBPhFCz.

7. Transient absorption spectra in solutions
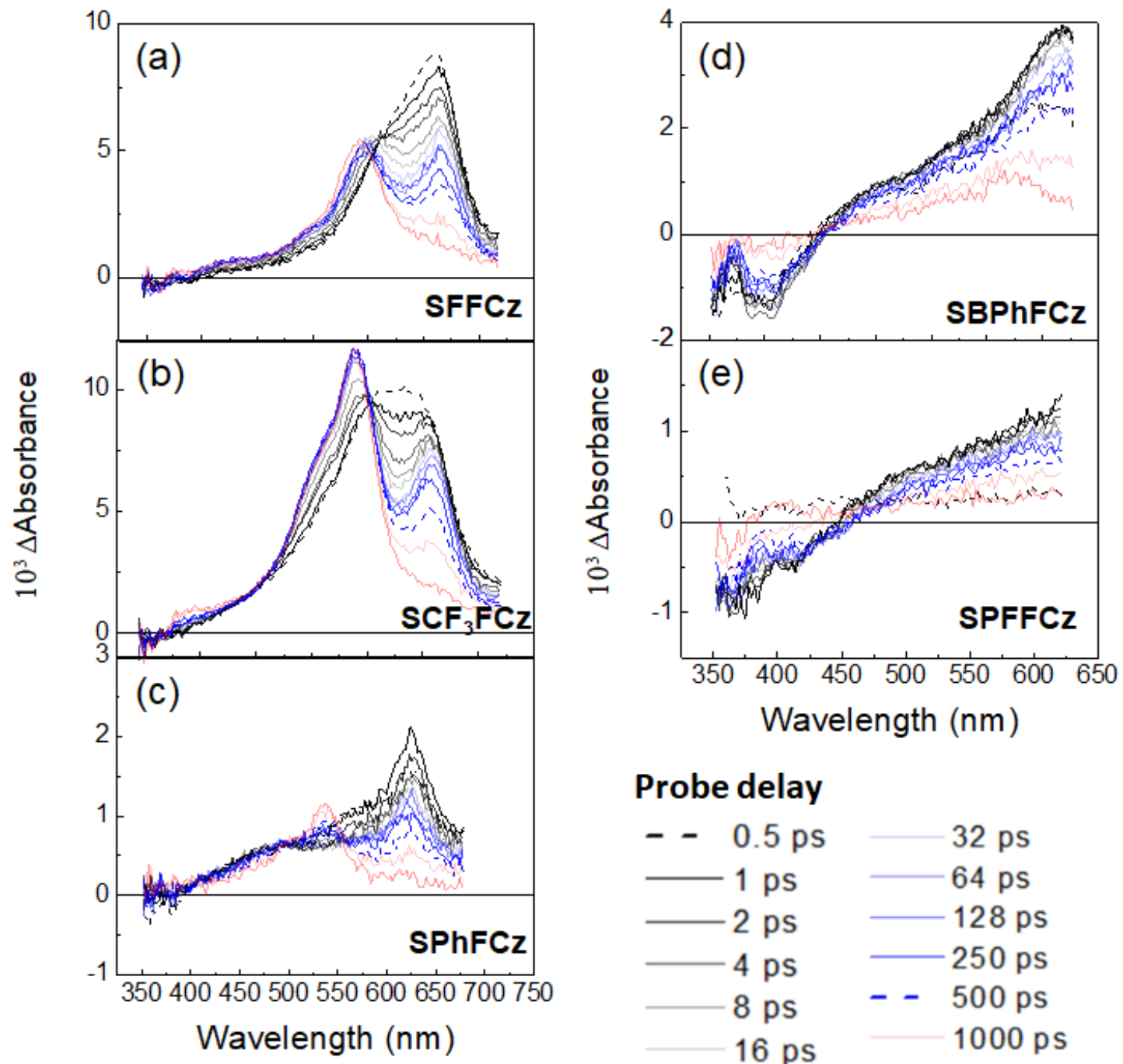

\section{Probe delay}

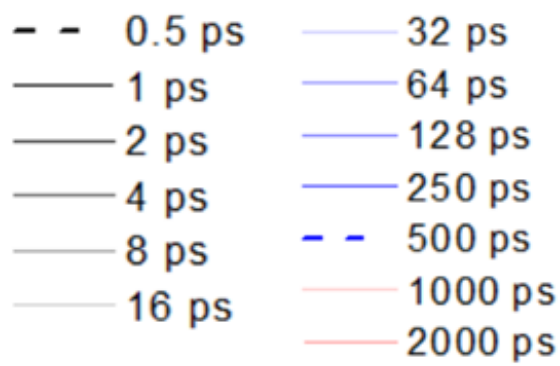

Figure S9. $\triangle \mathrm{A}$ spectra at different time delays of (a) SPFFCz, (b) SBPhFCz, (c) SFFCz, (d) $\mathbf{S C F}_{3} \mathbf{F C z}$, (e) SPhFCz in chloroform. Note that only SPFFCz and $\mathrm{SBPhFCz}$ exhibit stimulated emission as inferred from negative $\Delta \mathrm{A}$. 


\section{References}

[1] Q. Zhang, J. Liu, Q. Wei, X. Guo, Y. Xu, R. Xia, L. Xie, Y. Qian, C. Sun, L. Lueer, J. Cabanillas-Gonzalez, D. D. C. Bradley, W. Huang, Adv. Funct. Mater. 2018, 28, 1705824.

[2] M. J. Frisch, G. W. Trucks, H. B. Schlegel, G. E. Scuseria, M. A. Robb, J. R. Cheeseman, G. Scalmani, V. Barone, B. Mennucci, G. A. Petersson, H. Nakatsuji, M. Caricato, X. Li, H. P. Hratchian, A. F. Izmaylov, J. Bloino, G. Zheng, J. L. Sonnenberg, M. Hada, M. Ehara, K. Toyota, R. Fukuda, J. Hasegawa, M. Ishida, T. Nakajima, Y. Honda, O.

Kitao, H. Nakai, T. Vreven, J. A. Montgomery, Jr., J. E. Peralta, F. Ogliaro, M. Bearpark, J. J. Heyd, E. Brothers, K. N. Kudin, V. N. Staroverov, T. Keith, R. Kobayashi, J. Normand, K. Raghavachari, A. Rendell, J. C. Burant, S. S. Iyengar, J. Tomasi, M. Cossi, N. Rega, J. M. Millam, M. Klene, J. E. Knox, J. B. Cross, V. Bakken, C. Adamo, J. Jaramillo, R. Gomperts, R. E. Stratmann, O. Yazyev, A. J. Austin, R. Cammi, C. Pomelli, J. W. Ochterski, R. L. Martin, K. Morokuma, V. G. Zakrzewski, G. A. Voth, P. Salvador, J. J. Dannenberg, S. Dapprich, A. D. Daniels, O. Farkas, J. B. Foresman, J. V. Ortiz, J. Cioslowski, D. J. Fox, Gaussian 09, D.01 ed., Gaussian, Inc., Wallingford CT, 2013.

[3] Y. Niu, W. Li, Q. Peng, H. Geng, Y. Yi, L. Wang, G. Nan, D. Wang, Z. Shuai, Mol. Phys. 2018, 116, 1078-1090.

[4] Y. Niu, Q. Peng, C. Deng, X. Gao, Z. Shuai, J. Phys. Chem. A 2010, 114, 7817-7831. 